OAK RIDGE NATIONAL LABORATORY

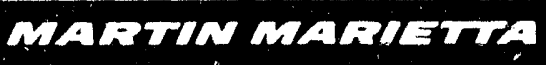

\title{
A Case Study of Optimization in the Decision Process: Siting Groundwater Monitoring Wells
}

\author{
Hal Cardwell \\ Dale Huff \\ Jeff Douthitt \\ Mike Sale
}

Environmental Sciences Division

Publication No. 4183

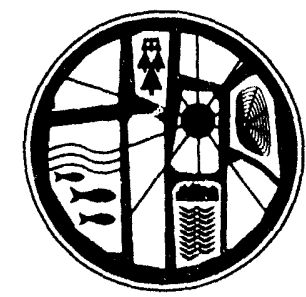

MARTIN MARIETTA ENERGY SYSTEMS, INC.

FOR THE UNITED STATES

DEPARTMENT OF ENERGY 
This report has been reproduced directly from the best available copy.

Available to DOE and DOE contractors from the Office of Scientific and Technical Information, P.O. Box 62, Oak Ridge. TN 37831; prices available from (615) 576-8401, FTS 626-8401.

Available to the public from the National Technical Information Service, U.S. Department of Commerce, 5285 Port Royal Rd., Springfield, VA 22161.

This report was prepared as an account of work sponsored by an agency of the United States Government. Neither the United States Government nor any agency thereof, nor any of their employees, makes any warranty, express or implied, or assumes any legal liability or responsioility for the accuracy, completeness, or usefulness of any information, apparatus, product, or process disclosed, or represents that its use would not infringe privately owned rights. Reference herein to any specific commercial product, process, or service by trade name. trademark, manufacturer, or otherwise, does not necessarily constitute or imply its endorsement, recommendation, or favoring by the United States Government or any agency thereof. The views and opinions of authors expressed herein do not necessarily state or reflect those of the United States Government or any agency thereof. 


$$
\begin{aligned}
& \text { ORNL/GWPO - } 006 \\
& (\text { ORN//N...3.21) }
\end{aligned}
$$

Ground Water Program Office

Environmental Sciences Division

\title{
A CASE STUDY OF OPTIMIZATION IN THE DECISION PROCESS:
}

\section{SITING GROUNDWATER MONITORING WELLS}

\author{
Hal Cardwell \\ Dale Huff \\ Jeff Douthitt \\ Mike Sale \\ December 1993
}

\author{
Prepared for \\ Ground Water Program Office \\ Budget Number PKC31402 \\ Environmental Sciences Publication Number 4183
}

\author{
Prepared by \\ Oak Ridge National Laboratory \\ managed by \\ MARTIN MARIETTA ENERGY SYSTEMS, INC. \\ for the \\ U.S. DEPARTMENT OF ENERGY \\ under contract DE-AC05-84OR21400
}


1. INTRODUCTION

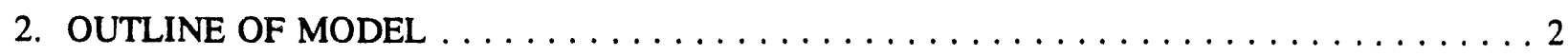

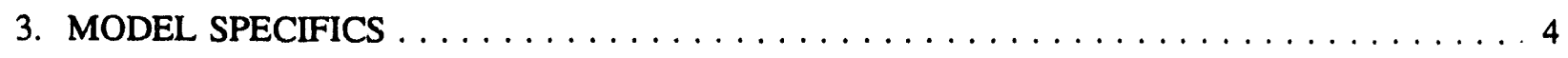

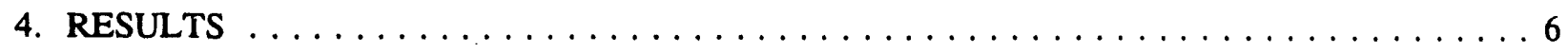

5. FEEDBACK: COMPARING MODEL SOLUTIONS WITH THE FINAL DECISIONS $\ldots \ldots$. 8

5.1 Reworking the Model $\ldots \ldots \ldots \ldots \ldots \ldots \ldots \ldots \ldots \ldots$

5.2 The Revised Model and Results $\ldots \ldots \ldots \ldots \ldots \ldots \ldots \ldots \ldots \ldots \ldots$

6. CONCLUSIONS, SUGGESTIONS FOR FURTHER WORK $\ldots \ldots \ldots \ldots \ldots \ldots$

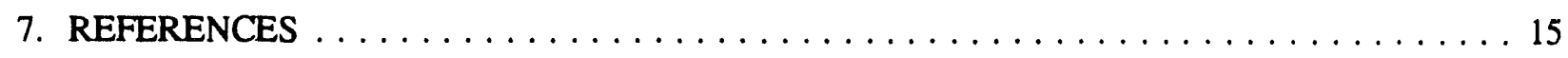

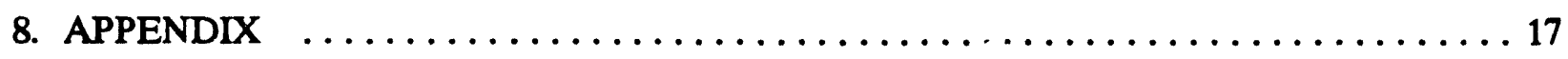




\section{LIST OF FIGURES}

Figure 1. Location of Northwest Plume at Paducah Gaseous Diffusion Plant in Paducah. Kentucky. 16

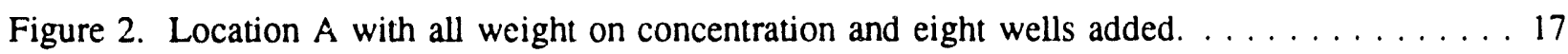

Figure 3. Location $B$ with all weight on concentration and eight wells added. . . . . . . 18

Figure 4. Location A with all weight on drawdown and eight wells added. . . . . . . . . 19

Figure 5. Location B with all weight on drawdown and eight wells added. . . . . . . . 20

Figure 6. Location $\mathrm{A}$ with equal weight on drawdown and concentration and six wells added. . . 21

Figure 7. Location A with equal weight on drawdown and concentration and eight wells added. . . 22

Figure 8. Location $A$ with equal weight on drawdown and concentration with ten wells added. . . 23

Figure 9. Location B with equal weights on concentration and drawdown with eight wells added. . 24

Figure 10. Location $B$ with equal weight on concentration and drawdown and six wells added. . . 25

Figure 11. Location B with equal weight on concentration and drawdown, ten wells added. . . . . 26

Figure 12. Location A with larger grid spacing, equal weights for drawdown and concentration,

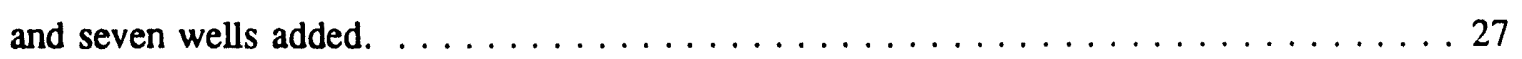

Figure 13. Location B with larger grid spacing, equal weights for drawdown and concent-ation,

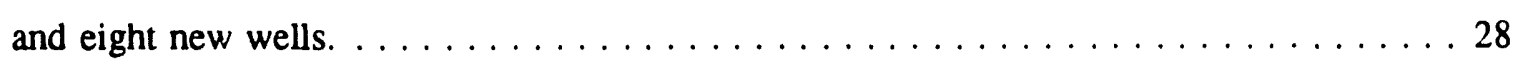

Figure 14. Trade-off between number of additional wells and the percent of total weight covered by optimal siting plan (Location $\mathbf{A}, \mathbf{S}=75) \ldots \ldots \ldots \ldots$

Figure 15. Trade-off between number of additional wells and the percent of total weight covered by optimal siting plan (Location $\mathrm{B}, \mathrm{S}=75) \ldots \ldots \ldots \ldots \ldots \ldots \ldots \ldots \ldots \ldots \ldots \ldots$

Figure 16. Actual well sites at Location $A$-- source site. $\ldots \ldots \ldots \ldots \ldots \ldots \ldots \ldots \ldots \ldots$

Figure 17. Actual well sites at Location B -- toe-of-the-plume site. $\ldots \ldots \ldots \ldots \ldots \ldots \ldots$

Figure 18. Preliminary network design, eight monitoring wells. $\ldots \ldots \ldots \ldots \ldots \ldots$

Figure 19. Location B with regular grid spacing, revised formulation, and equal weights on

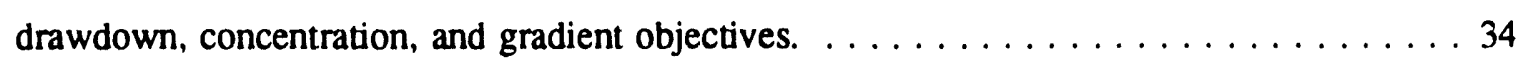

Figure 20. Location B with larger grid spacing, revised formulation, and equal weights on drawdown, concentration, and gradient objectives. $\ldots \ldots \ldots \ldots \ldots \ldots \ldots \ldots \ldots \ldots \ldots$

Figure 21. Location B with larger grid spacing, revised formulation, and all weight on drawdown. 36 


\begin{abstract}
Optimization is one of the tools available to assist decision makers in balancing multiple objectives and concems. In a case study of the siting decision for groundwater monitoring wells, we look at the influence of the optimization models on the decisions made by the responsible groundwater specialist. This paper presents a multi-objective integer programming model for determining the location of monitoring wells associated with a groundwater pump-and-treat remediation. After presenting the initial optimization results, we analyze the actual decision and revise the model to incorporate elements of the problem that were later identified as important in the decision-making process. The results of a revised model are compared to the actual siting plans, the recommendations from the initial optimization runs, and the initial monitoring network proposed by the decision maker.
\end{abstract}




\section{ACKNOWLEDGEMENTS}

Additional support was provided by an appointment to the Oak Ridge National Laboratory Postdoctoral Research Associates Program administered jointly by the Oak Ridge Institute for Science and Engineering and Oak Ridge National Laboratory. 


\section{INTRODUCTION}

Plans to implement pump-and-treat remediation programs at the Paducah Gaseous Diffusion Plant (Fig. 1) in Paducah, Kentucky, prompted the design of two new groundwater monitoring well networks to evaluate the effectiveness of the remediation efforts. A multi-objective integer programming model was used to identify the appropriate number and location of these monitoring wells. The responsible groundwater professionals identified two parameters of interest to use in the siting decisions: (1) contaminant concentration and (2) change in head or drawdown caused by pumping from the extraction wells.

An Interim Record of Decision, issued by the U.S. Environmental Protection Agency (EPA), required the installation of two new pump-and-treat systems at Paducah: one located near the source of the Northwest plume and the other near the toe of the plume hot spot. The hot spot is defined as contaminant concentrations $>1000$ parts per billion (ppb). The contaminant of interest is trichloroethylene (TCE) and is believed to enter the groundwater system through the dissolution of dense nonaqueous-phase liquid (DNAPL) pools beneath closed burial areas (Clausen et al. 1993). The plume exists within the regional gravel aquifer, which ranges between 10 and $50 \mathrm{ft}$ in thickness at a depth of $\sim 60 \mathrm{ft}$. The plume covers $\sim 2$ miles $^{2}$ and is migrating generally northward toward the Ohio River. The extraction wells at the toe of the plume site are intended to hydraulically control the hot spot, whereas the south well field is intended to isolate the DNAPL source zone and prevent further growth of the plume.

This paper describes the optimization models developed for the siting problem and provides an analysis of the decisions actually made. Since we had only $\sim 3$ weeks to develop a monitoring network plan to submit to regulators, we chose a fairly simple optimization model to identify potential sites. Following data collection and model runs, results were presented to the responsible groundwaier specialist. Although the groundwater staff and the optimization team communicated throughout the project, time constraints prevented multiple iterative revisions of the initial optimization model. After the monitoring sites were selected, the optimization team reevaluated the optimization model to determine factors that the original formulation omitted. The following is a description of the initial modeling effort, the optimization modeling results, the actual siting plan, and the development and results of the revised model. 


\section{OUTLINE OF MODFL}

Our approach modifies a fairly simple integer programming model [Hudak and Loaiciga 1992] to determine the best location for new monitoring wells. Integer programming is an optimization tool that differs from conventional linear programming by allowing integer restrictions on decision variables (Phillips et al. 1976). The approach requires discretization of the area of interest into a grid. Associated with each grid point is a nodal weight, which quantifies that sites' relative importance as a sampling location. Our approach uses multiple parameters to determine this nodal weight; the weight can be based on the expected concentration at that location, the expected drawdown at the site, another parameter of interest, or any combination of these parameters. The model requires values for each parameter of interest at each node point. This grid and its associated nodal weights provide the basic information needed to determine the optimal location of monitoring wells. The location of existing wells and the number of wells to be sited are also required. Paducah groundwater staff supplied this information. The formulation is adapted from the maximal covering location model proposed by Church and ReVelle (1974) for siting emergency facilities. This location model finds solutions that cover the maximum amount of weight within a grid by appropriately siting a specified number of facilities (monitoring wells). The objectives and constraints of the model are as follows:

$$
\text { Maximize } Z=\sum_{i \in I} w_{i} y_{i}
$$

$$
\begin{aligned}
& \text { such that } \sum_{j \in N_{i}} x_{j} \geq y_{i} \quad \text { for all } i \in I \\
& \sum_{j \in J} x_{j}=P \\
& x_{j}=(0,1) \quad \text { for all } j \in J \\
& y_{i}=(0,1) \quad \text { for all } i \in l \\
& x_{j}=1 \quad \text { for all } j \in J_{p}
\end{aligned}
$$

where $Z=$ Objective that we seek to maximize -- the weighted sum of nodes that are covered $W_{i}=$ weight at each node 
$x_{j}=1$ if a well is installed at site $j, x_{j}=0$ otherwise

$y_{i}=1$ if a node $i$ is covered, $y_{i}=0$ otherwise

$P=\quad$ total number of wells (including existing and extraction) to be located

$I=\quad$ set of nodes in discretized network

$J=\quad$ set of possible well sites

$J_{p}=\quad$ set of nodes $j$ occupied by preexisting wells

$N_{i}=\left[j / d_{i j} \leq S\right]$ set of nodes within distance $S$ of node $i$

$d_{i j}=$ shortest distance from node $i$ to node $j$

$S=$ predetermined radius of coverage for all wells

The objective (Eq. 1) maximizes the weighted coverage of the nodes in the network. The first constraint set (Eq. 2) defines a node $(i)$ as either covered $\left(y_{i}=1\right)$ or uncovered $\left(y_{i}=0\right)$. The node is covered only if it is within an acceptable distance $\left(d_{i j}\right)$ of a node where a well is installed $\left(x_{j}=1\right)$. The set of nodes that are close enough $\left(d_{i j} \leq S\right)$ to node $i$ to result in coverage is denoted by set $N_{i}$. This radius of coverage, $S$, is determined before the optimization and can be varied between optimization runs. Its value can be alternately thought of as one-half of the minimum acceptable distance between wells or as the maximum extent of influence of a given monitoring well. Equation 3 restricts the number of wells $\left(x_{j}=I\right)$ to $P$. We assume that the extraction wells serve as monitoring wells. The third and fourth sets of constraints (Eqs. 4 and 5) define $x_{j}$ and $y_{i}$ to be zero--one variables. The final constraints (Eq. 6) account for existing wells by setting $x_{j}=l$ if there is an existing monitoring well at node $j$.

Although this model is formed as an integer program, its structure is such that it can frequently be solved by conventional linear programming. Using linear programming techniques greatly reduces the solution time and allows the problem to be solved with inexpensive, readily available software routines. To convert the problem to a linear programming structure, the integer constraints on $x_{j}$ and $y_{i}$ (Eqs. 4 and 5) are relaxed, and the variables are given an upper bound of one and a lower bound of zero. Although not all cases of this relaxed mixed integer program solve to integer values, $>80 \%$ of the runs in this work did. More information on the specific structure necessary to obtain integer solutions to relaxed integer programming problems can be found in ReVelle (1993).

In this effort we assume the groundwater system is adequately represented by a twodimensional modeling effort and assume the aquifer to be homogeneous and isotropic. These 
assumptions were considered appropriate for the narrow sand-and-gravel aquifer at the Paducah site. We note that the mathematical framework is flexible, and these assumptions could be relaxed. Since the model is concerned only with the distance between nodes, it is insensitive to the number of dimensions. To model heterogeneous anisotropic systems, the sets $N_{i}$ could be specifically defined for each node.

\section{MODEL SPECIFICS}

The model above was used as the basis for the modeling work, and multiple optimizations were done using various weighting functions for the nodes $\left(W_{i}\right)$, multiple values for the allowable number of wells, $P$, and different values for the radius of coverage, $S$. The areas of interest were two locations where extraction wells were to be installed; one location near the source of the contamination (Location A) and one near the toe of the hot spot (Location B). Two extraction wells are planned for each site. At each of these locations of $2000 \mathrm{ft} \times 2000 \mathrm{ft}$, Paducah groundwater program staff provided estimates of both TCE concentration and drawdown for a $40 \times 40$ orthogonal grid (1600 nodes). Nodes were spaced $50 \mathrm{ft}$ apart. An existing numerical flow model of the site was used to estimate drawdown. Concentration weights were assigned by overlaying the grid on interpreted maps of the plume. Staff also provided information on the location of the planned extraction wells and of three existing monitoring wells at the source area (Location A).

Two constituents were considered important in the determination of nodal weights, $w_{i}$ : drawdown (change in hydraulic head) and concentration (of TCE). Symbolically we refer to the contributions of each parameter to $W_{i}$ as $W_{i, m}$, where $m$ is the index for the parameter $(m \in\{$ draw, $T C E\})$. In order to make the magnitudes of these two parameters comparable, the raw parameter data were modified by a simple normalization: drawdown values were divided by the maximum drawdown, and for Location A, TCE concentrations were likewise divided by the maximum concentration. At the nose of the plume (Location B) there was specific interest in tracking the $1000 \mathrm{ppb}$ concentration contour, and hence the nodal weights for concentration were given by an arbitrary, nonsmooth function as shown below: 
Location A

$$
\begin{gathered}
W_{i, d r a w}=\frac{\text { Drawdown }_{i}}{\text { Maximum Drawdown }} \\
W_{i, T C E}=\frac{[T C E]_{i}}{\text { Maximum }[T C E]}
\end{gathered}
$$

\section{Location B}

$$
\begin{gathered}
W_{i, \text { draw }}=\frac{\text { Drawdown }_{i}}{\text { Maximum Drawdown }} \\
=\left\{\begin{array}{cc}
\frac{[T C E]_{i}}{1000} & \text { if }[T C E]_{i} \leq 1000 \\
1+.05\left(\frac{[T C E]_{i}}{1000}-1\right) & \text { if }[T C E]_{i}>1000
\end{array}\right.
\end{gathered}
$$

These functions assign a value for each parameter to every node. Various objective functions (Eq. 1) can then be generated by using different linear combinations of the nodal values. This can be expressed as follows:

$$
W_{i}=\sum_{\text {all } m} \lambda_{m} \cdot W_{i, m} \quad \text { for all } i \in l
$$

where $\lambda_{m}$ is an arbitrary weight assigned to each parameter. These weights $\left(\lambda_{m}\right)$ reflect the relative importance of the parameter (drawdown or TCE concentration) in the siting decision. Arbitrarily we assign them to sum to one.

This work considered three such linear combinations: the nodal weights solely dependent on concentration $\left(\lambda_{\text {draw }}=0, \lambda_{T C E}=1\right)$, nodal weights solely dependent on drawdown $\left(\lambda_{\text {draw }}=1\right.$, $\left.\lambda_{T C E}=0\right)$, and nodal weights equally dependent on the two $\left(\lambda_{d r a w}=0.5, \lambda_{T C E}=0.5\right)$. Values for parameter weights other than $1,0.5$, and 0 could have been used but were not. Weighting of objectives to produce multiple, noninferior solutions is a standard technique in multi-objective programming (Cohon, 1978). Generating multiple solutions allows the decision maker both to pick among siting plans that satisfy the objectives to various degrees and to reevaluate the relative importance of the objectives.

For Location A, optimizations were performed using 9, 11,13,15, 17, and 21 total wells (4 to 16 additional wells). For Location B, optimizations were performed using 8, 10,12, 14, 16, and 18 total wells (6 to 16 additional wells). The radius of coverage for a monitoring well, $S$, was difficult to vary because of computer limitations. The problem size grows rapidly with increases in $S$ and the 
accompanying increase in $N_{i}$, the number of nodes within distance $S$ of node $i$. Although plans were to vary $S$ from $75 \mathrm{ft}$ to $250 \mathrm{f}$, only two cases were performed: $S=75 \mathrm{ft}$, and $S=150 \mathrm{ft}$. In order to solve the case of $S=150 \mathrm{ft}$, the number of nodes was reduced from 1600 to 400 by doubling the grid spacing to $100 \mathrm{ft}$.

The $20 \times 20$ problems with $S=150 \mathrm{ft}$ solved in a few minutes on a $16 \mathrm{MHz}, 386 \mathrm{PC}$ using GAMS/MINOS. The $40 \times 40$ problems with $S=75 \mathrm{ft}$ took. slightly longer. GAMS is a commercially available algebraic modeling system that can use a variety of standard mathematical programming solvers including MINOS. Although using 1600 nodes with $S=150 \mathrm{ft}$ created a problem that was too large to be solved in an acceptable time limit on a PC, it solved in a few minutes on a UNIX based workstation using GAMS/CPLEX.

\section{RESULTS}

Figures 2 to 13 show results for multiple optimizations using various numbers of wells $(P)$, parameter weights $\left(\lambda_{m}\right)$, and radii of coverage $(S)$. for both Location A and Location B. The maps are oriented so that north is to the right side of the page. Figures 14 and 15 show trade-offs between the percentage of weight covered and the number of wells for a number of different scenarios. Figures 10 and 11 show results using a different radius of coverage and the coarser (100 ft) grid spacing.

For both locations, when all the weight is due to concentration $\left(\lambda_{d r a w}=0, \lambda_{T C E}=1\right)$, new wells are located to cover the areas with highest concentration: the lower left quadrant of the grid for Location A (Fig. 2) and the upper left quadrant at Location B (Fig. 3). When drawdown is the sole parameter considered $\left(\lambda_{\text {Draw }}=1, \lambda_{T C E}=0\right)$, the optimization model places monitoring wells in a roughly concentric pattern around the planned extraction wells at both locations (Figs. 4 and 5 ).

For cases in which drawdown and concentration are equally weighted $\left(\lambda_{\text {Draw }}=\lambda_{\text {TCE }}=.5\right)$, results using various numbers of wells can indicate priority areas for coverage for both Locations $A$ and B. In both locations the first priority is to cover the areas of high concentration (i.e. the lower left quadrant for case A and the upper left quadrant for Location B). As the number of wells are increased (Figs. 6 to 11), the additional wells are located around the extraction wells. This is a secondary priority area. The concept of priorities is also useful in analyzing results of cases in which the radius of coverage $(S)$ is expanded (Figs. 12 and 13). Once the first priority area is covered, the second priority sites begin 
to be covered. As the radius of coverage is increased, fewer wells are necessary to cover the first priority area, and thus fewer total wells are necessary to have wells sited in secondary priority areas.

Any analysis of results generated using a weighted objective function must consider the form of the weighting functions for the two parameters. For both locations, the raw drawdown data were simply divided by the maximum drawdown. Since predicted drawdown at the extraction wells was just over twice as high as that at the fringes of the nodal network, nodal weights range from -0.45 to 1.00 . The analogous function was employed for concentration at Location A, but with raw TCE concentrations ranging from 0 to $100,000 \mathrm{ppb}$, the resultant weights were between 0 and 1 . Most of the raw values were either $10,000 \mathrm{ppb}$ or $1000 \mathrm{ppb}$, which translates into weights of 0.10 or 0.01 . This causes the optimization algorithm to place higher priority on covering locations with high concentration (and midlevel weights for drawdown) than on areas with high drawdown (and negligible weight associated with concentration). For Location B, all raw concentration data were $1000 \mathrm{ppb}$ or less, denoting a range of 0 to 1 for the transformed values. Again this would lead the optimization algorithm to cover areas of peak concentration instead of high drawdown areas.

Trade-offs between percent coverage and number of wells (Figs. 14 and 15) illustrate the expected decrease in the additional weight covered by each additional well. This is especially true for Location $A$ when all the weight is on concentration $\left(\lambda_{d r a w}=0, \lambda_{T C E}=1\right)$; a small number of nodes with extremely high TCE concentrations contribute a majority of the total weight. The decreasing additional coverage with increases in the number of wells is less evident in the other cases. This is due to a more even distribution of nodal weights in these scenarios, as discussed above.

In analyzing the model results, we also must be aware of the possibility of altemative optima. Alternative optima are different solutions that have the same, optimal, objective function value as the solution generated. Considering the effective discretization of concentration, alternative optima are likely to exist, especially in those formulations that consider only concentration in the objective. Hence, other equally good siting plans may exist. This work did not investigate altemative optima but merely notes the possibility and, in fact, probability of their existence. 


\section{FEEDBACK: COMPARING MODEL SOLUTIONS WITH THE FINAL DECISIONS}

After considering the results of the optimization model, the decision maker chose the locations of the monitoring wells (Figs. 16 and 17). He also identified three additional factors that he considered in the decision making process:

1. Four new monitoring wells will be sited for Location A and five for Location B.

2. Wells should not be sited near environmentally sensitive areas (wetlands provide "one of the strictest controls on location" of the wells). Site evaluations had identified environmentally sensitive areas near both well fields (floodplains, wetlands, and threatened or endangered species).

3. For Location $B$, the weighting function should "place more emphasis on the stagnation zone and capture zone boundaries."

In addition to the concems explicitly expressed by the decision maker, the optimization team identified two other factors that influenced the decision at Location B:

4. the 1000-ppb boundary of the contaminant plume, and

5. a desire to site wells both up- and downgradient from the extraction wells.

The decision maker expressed his satisfaction with the results and particularly commented on the value of the trade-off graphs showing the increase in percent coverage as a function of number of wells (Figs. 14 and 15). If we define the success of the optimization effort as providing the decision maker with information that he finds useful, then the optimization was successful. Another way to evaluate the effectiveness of the optimization is to note the differences between the actual siting decisions and a preliminary (preoptimization) networt. design (Fig. 18). We see that the preliminary configuration sites wells in two lines emanating radially from the extraction well and sites two wells downgradient. The optimization generally suggested wells spaced in a circular pattem around the wells (Figs. 4, 5, and 12); this is similar to the decision made. We note that the relative locations of the extraction wells for Location A were changed in the actual siting plan.

To improve the real usefulness of the optimization technique to decision makers, we use the actual siting decisions to suggest appropriate modifications to the optimization model. Here we incorporate the additional concems cited above. So is not to second-guess the groundwater specialist / decision maker we resist the temptation to evaluate the final siting plan using the criteria previously 
identified in the model. Instead we concentrate on those aspects of the decision that the model failed to incorporate. For brevity and clarity, we perform this postdecision analysis for Location B only.

\subsection{Reworking the Model}

To address the five additional concerns, we modify the model structure outlined in Eqs. 1 to 11 . While the original problem allowed from 6 to 16 monitoring wells, the reviced problem allowed 5 ( $P=7$, 5 monitoring plus 2 extraction wells). To address the second concern, we restrict the set of possible well sites, $J$, to exclude environmentally sensitive sites. This new set., $J_{e^{\prime}}$ contains all environmentally acceptable potential well sites.

The third revision of the initial model involves the stagnation and capture zones. The stagnation zone is the area where the average groundwater flow is zero. It occurs in those areas where the gradient produced by the extraction wells is equal in magnitude to and opposite in direction from the natural flow gradient. The resultant gradient. $\nabla$, is their sum and represents the spatial change in head. This is distinct from drawdown, which is the change in head between the extraction and no-extraction scenarios. The capture zone is the area where groundwater flows to the extraction wells (a nonzero resultant gradient). The border between the capture zone and the zone where groundwater does not flow to the extraction wells is referred to as the capture zone boundary; the stagnation zone is its downgradient end. Note that the capture zone boundary and the stagnation zone are neither rigid lines nor large areal expanses; both are narrow boundary areas. Here we define the stagnation zone as the area where the resultant gradients and velocities are low, though perhaps not exactly zero. Similarly, the capture zone boundary is defined as an area where the resultant gradients and velocities in the direction of the extraction wells are low, but not necessarily zero.

To use the capture zone boundary and stagnation zone in the optimization model requires grid point data analogous to that for concentration and drawdown. These grid point data are then used to assign nodal weights for the gradient-based objective. Here we arbitrarily select the gradient-based nodal weighting function, $w_{i, \nabla}$ :

$$
W_{i, \nabla}= \begin{cases}1 & \text { if } i \in \text { stagnation zone } \\ .5 & \text { if } i \in \text { capture zone boundary } \\ 0 & \text { otherwise }\end{cases}
$$


Since fewer nodes fall within the stagnation zone than the capture zone boundary, we assign a higher weight to these nodes.

The 1000-ppb concentration boundary is the fourth factor and was considered in the initial meeting with the groundwater staff. The original concentration-based nodal weighting function for Location B (Eq. 10) was designed to give special importance to this boundary by making the marginal weight of concentrations $<1000 \mathrm{ppb}$ significantly less than that for concentrations $\geq 1000 \mathrm{ppb}$. However, this function did not encourage wells to be sited along the boundary since the marginal weight for increasing concentration was positive, if small. To further emphasize the 1000-ppb concentration level, the postdecision analysis considered a function, proposed at the initial meeting, that assigns a small nodal weight at low concentrations, assigns a maximum at a concentration of slightly $<1000 \mathrm{ppb}$, and then assigns lower values. It is shown below.

$$
w_{i,[T C E]}=\frac{1}{1+\frac{\left|C_{i}-1000\right|}{500}}
$$

Experience with this function showed that it was inappropriate for Location B due to the nature of the concentration data. TCE concentration values were recorded in discrete increments of either 5, 100 . or $1000 \mathrm{ppb}$ of concentration. Whereas using Eq. 13 in the objective would site wells on a boundary if the data reflected the true continuum of concentration, a discrete representation of the data deemphasized this boundary. Instead an arbitrary function similar to that used for the gradient-based objective was chosen to replace the earlier concentration-based function. This concentration "boundary" function is described below:

$$
W_{i,[T C E]}= \begin{cases}1 & \text { if } i \in 1000 \text { ppb boundary zone } \\ 0 & \text { otherwise }\end{cases}
$$

where a node was considered to be in the boundary zone if any node within $75 \mathrm{ft}$ of it had a markedly different concentration value.

To address the fifth concern we add constraints requiring at least two wells both up- and downgradient. 


$$
\begin{aligned}
& \sum_{j \in U} x_{j} \geq 2 \\
& \sum_{j \in D} x_{j} \geq 2
\end{aligned}
$$

where $U$ is the set of all potential well sites upgradient of the extraction wells and $D$ is the set of all potential well sites downgradient of the extraction wells. We note that using the stagnation zone in the objective may make these constraints redundant.

\subsection{The Revised Model and Results}

The resulting, modified model structure is expressed as:

$$
\begin{aligned}
& \text { Maximize } Z=\sum_{i \in I} W_{i} y_{i} \\
& \text { such that } \quad \sum_{j \in N_{i}} x_{j} \geq y_{i} \quad \text { for all } i \in l \\
& \sum_{j \in J_{e}} x_{j}=7 \\
& x_{j}=(0,1) \quad \text { for all } j \in J \\
& y_{i}=(0,1) \quad \text { for all } i \in I \\
& x_{j}=1 \quad \text { for all } j \in J_{p} \\
& \sum_{j \in U} x_{j} \geq 2 \\
& \sum_{j \in D} x_{j} \geq 2
\end{aligned}
$$

where $W_{i} \equiv$ weight at each node

$$
W_{i}=\sum_{m \in M} \lambda_{m} \cdot W_{i, m} \quad \text { for all } i \in I
$$

$M \equiv$ set of parameters which serve as objectives $\{$ draw, $[\mathrm{TCE}], \nabla$ \} 


$$
\begin{aligned}
W_{i, d r a w} & =\frac{12}{\text { Maximum Drawdown }} \\
W_{i,[T C E]} & = \begin{cases}1 & \text { if } i \in 1000 \text { ppb boundary zone } \\
0 & \text { otherwise }\end{cases} \\
W_{i, \nabla} & = \begin{cases}1 & \text { if } i \in \text { stagnation zone } \\
.5 & \text { if } i \in \text { capture zone boundary } \\
0 & \text { otherwise }\end{cases}
\end{aligned}
$$

Figures 19 and 20 show results of the revised model using equal weights for the three objectives - drawdown, concentration toundary, and capture/stagnation zone. The environmentally sensitive nodes are identified with an $S$, and the new concentration boundary function is denoted "bound". The results can be compared with the actual siting plan for Location B (Fig. 17), with the results from the initial optimization model (Figs. 3, 5, 7, 9, 11, and 13) and with the well siting plan developed by the decision maker prior to the modeling effort (Fig. 18). Our revised model was not able to mimic the decision maker's results. The closest model solution to the actual decision was when all the weight in the objective function was placed on drawdown with a 150 - $\mathrm{ft}$ radius of coverage for each well (Fig. 21). All of the solutions with the larger ( $150 \mathrm{ft}$ ) radius of coverage were closer to the siting plans selected.

\section{CONCLUSIONS, SUGGESTIONS FOR FURTHER WORK}

Siting groundwater monitoring wells presented an excellent opportunity to apply systems analysis tools to a decision problem and show their value to decision makers. Although iterative model development was not possible because of the time frame of this application, the success of this optimization exercise can be measured in various ways. First, discussions with groundwater staff of appropriate objective functions focused attention on the objectives of the monitoring program -- whether the goal was to examine the region of increased drawdown, or if it was to track the $1000 \mathrm{ppb}$ concentration contour. Second, the optimization results provided a range of possible solutions that could be compared with those of a more subjective design that was based on professional judgment. The optimization model showed general patterns of recommended well sites that reflected the two objectives 
initially considered. The result was that groundwater specialists selected a revised design that involved fewer wells than originally planned and generally followed the pattem identified in the optimization runs.

The attempts at further quantification of the problem are more difficult to evaluate. Although environmentally sensitive areas and requirements for wells both up- and downgradient were easily incorporated, the changes to the objectives did not produce results that mimicked the actual decision. Instead we contend that the results of the revised model could best be used by the decision maker to further clarify the objectives of the monitoring program.

We stress that this methodology is fairly simple, and easy to implement. Although the model can use multiple parameters with variable weights and incorporate environmental and other constraints, it remains an integer formulation that can usually be solved with readily available linear programming software. This study of an actual siting problem serves as an example of an easily adaptable, readily accessible tool for decision makers.

Time and available computer resources limited the scope of the project, and thus suggestions for further work abound. Various other combinations of the relative weight of concentration and drawdown could be studied, as could different nodal weighting functions for transforming the raw data. One altemative would be to fully normalize values for drawdown and see if the areas of priority shift closer to the center of the grid. Likewise the concentration values could be normalized on a logarithmic scale if that is deemed appropriate. The radius of coverage could also be increased. To reflect the hydrogeology and the differences between parameters, this radius could be made dependent on the parameter of interest or on the region of the grid. Another variant on the approach used here would still base siting decisions on nodal weights but require that monitoring wells be located so that every node in the network is within a prespecified distance of a monitoring well. This would ensure greater spatial dispersion of the monitoring wells. Alternatively, if removal of preexisting wells was under consideration, a modified approach could find the optimal combination of existing and new wells.

Similar systems analysis techniques can also be used to help plan for more complex remediation activities. If future work includes installing a barrier wall to contain contaminant transport, then our technique could be adapted to site monitoring wells for measuring the effectiveness of this remediation technique. Other approaches can determine efficient pumping rates from pump-and-treat wells and the optimal location for corresponding monitoring wells. The optimal sampling frequency of monitoring wells can be evaluated as can the effectiveness of an existing network of monitoring wells. The uncertainty in the hydraulic conductivity at the site or in the measurement of the existing flow field can be accommodated though a number of techniques including stochastic programming, simulated annealing. 
and kriging. Other approaches include reliability and regret-based objectives and constraints. These efforts represent one set of specific applications for systems analysis approaches to determine an appropriate monitoring well network configuration.

We urge that future decisions employ optimization earlier in the decision process and in an iterative manner. The use of optimization early in the decision process can clarify goals, identify areas of uncertainty, and reduce program costs. An iterative process makes for better, more useful models.

Finally, we note the applicability of systems analysis techniques at all stages in the planning process in large-scale groundwater problems (Freeze et al. 1990). 


\section{REFERENCES}

Church, R. L., and C. ReVelle. 1974. The maximal covering location problem. Papers of the Regional Science Association. 32:101-118.

Clausen, J. L., J. Zutman, and N. Farrow. 1993. Characterization of the Northwest Plume Utilizing Discrete-Depth Sampling System. Martin Marietta Energy Systems, Inc., Paducah Gaseous Diffusion Plant, KY/ER-22. Paducah, Kentucky.

Cohon, J. 1978. Multiobjective Programming and Planning, Academic Press, San Diego.

Freeze, R. A., J. Massmann, L. Smith, T. Sperling, and B. James. 1990. Hydrogeological decision analysis: 1. A framework. Ground Water. 28(5):738-766.

Hudak, P. F., and H. Loaiciga. 1990, A location modeling approach for groundwater monitoring network augmentation, Water Resour. Res. 28:643-649.

Phillips, D. T., A. Ravindran, and J. J. Solberg. 1976. Operations Research: Principles and Practice, John Wiley \& Sons, New York.

ReVelle, C. 1993. Facility siting and integer-friendly programming, Eur. J. Oper. Res., 65:147-158. 
8. APPENDIX 


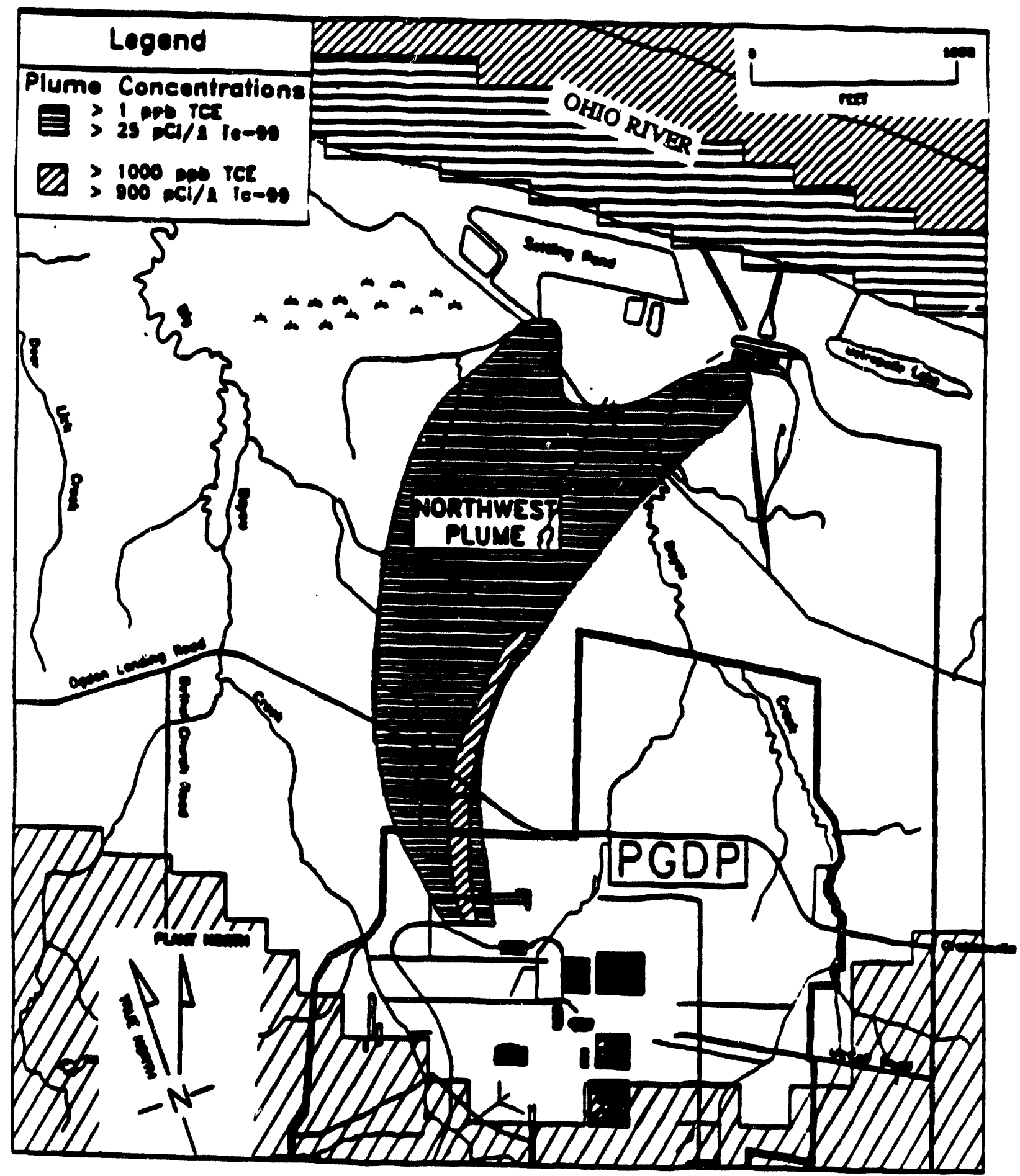

Fig. 1. Location of Northwest Plume at Paducah Gaseous Diffusion Plant in Paducah, Kentucky. 
Radius of coverage $(S)=75.0$

Total number of wells $(P)=13$

Percentage covered $=61.43$

Weight for drawdown $\left(\lambda_{\text {draw }}\right)=0.00$

Weight for concentration $\left(\lambda_{\text {conc }}\right)=1.00$

$$
\langle--y-->>
$$

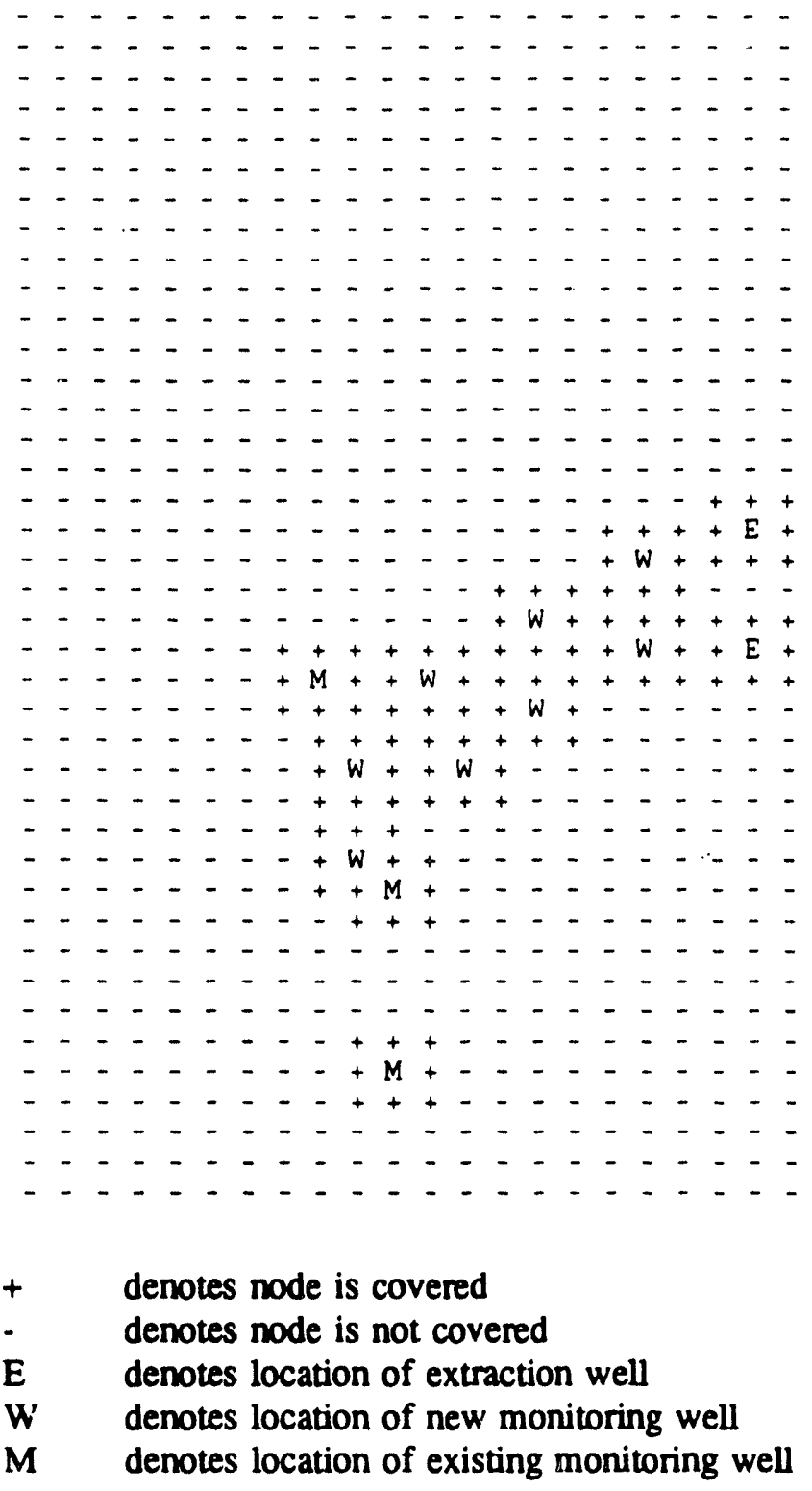

Fig. 2. Location A with all weight on concentration and eight wells added. 
Radius of coverage $(S)=75.0$

Total number of wells $(P)=10$

Percentage covered $=20.46$

Weight for drawdown $\left(\lambda_{\text {draw }}\right)=0.00$

Weight for concentration $\left(\lambda_{\text {conc }}\right)=1.00$

$\langle--y-\cdots>$

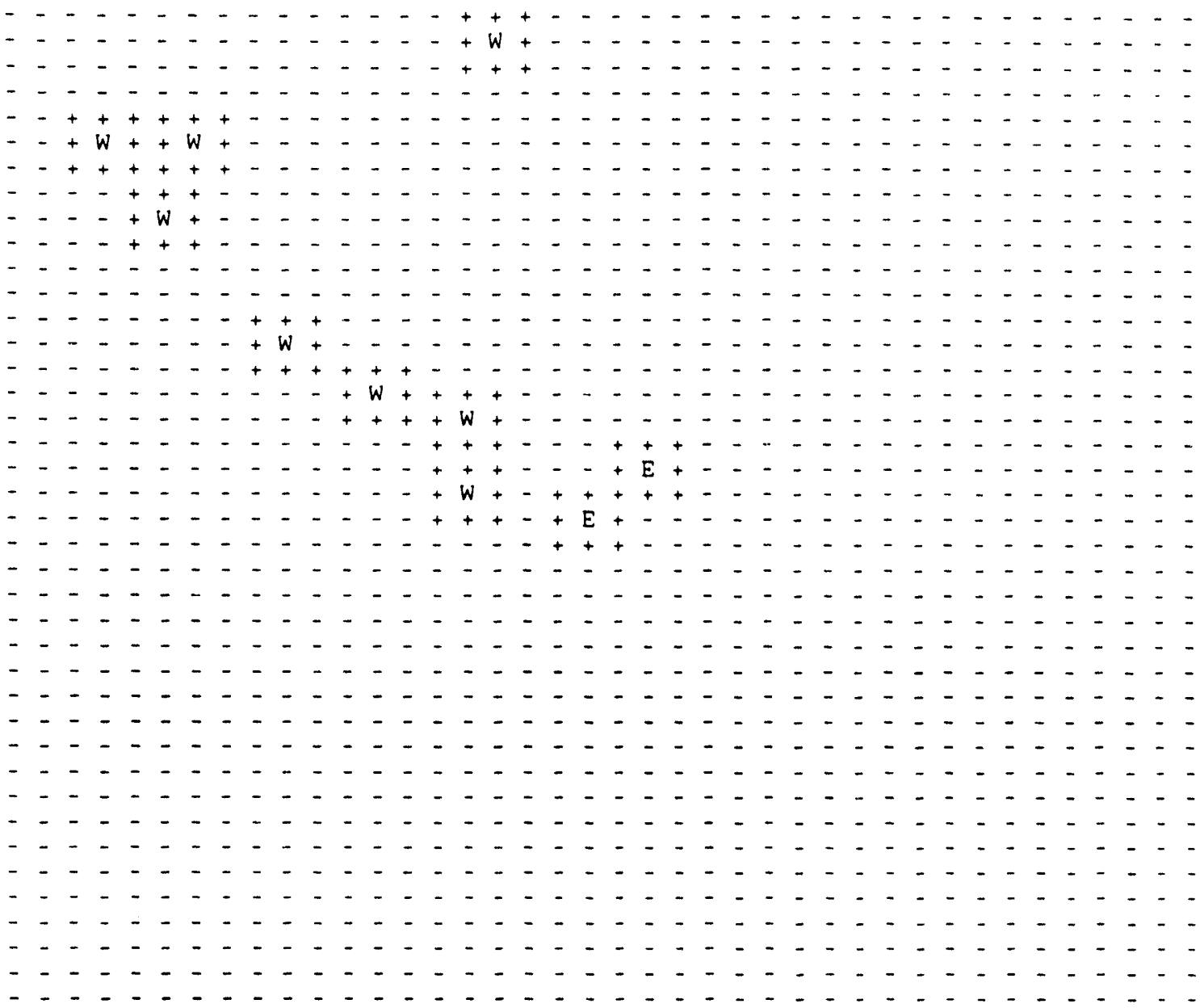

$+\quad$ denotes node is covered

- denotes node is not covered

E denotes location of extraction well

W denotes location of new monitoring well

M denotes location of existing monitoring well

Fig. 3. Location B with all weight on concentration and eight wells added. 
Radius of coverage $(S)=75.0$

Total number of wells $(P)=13$

Percentage covered $=9.42$

Weight for drawdown $\left(\lambda_{\text {draw }}\right)=1.00$

Weight for concentration $\left(\lambda_{\text {conc }}\right)=0.00$

$\langle-\cdots y-\cdots>$

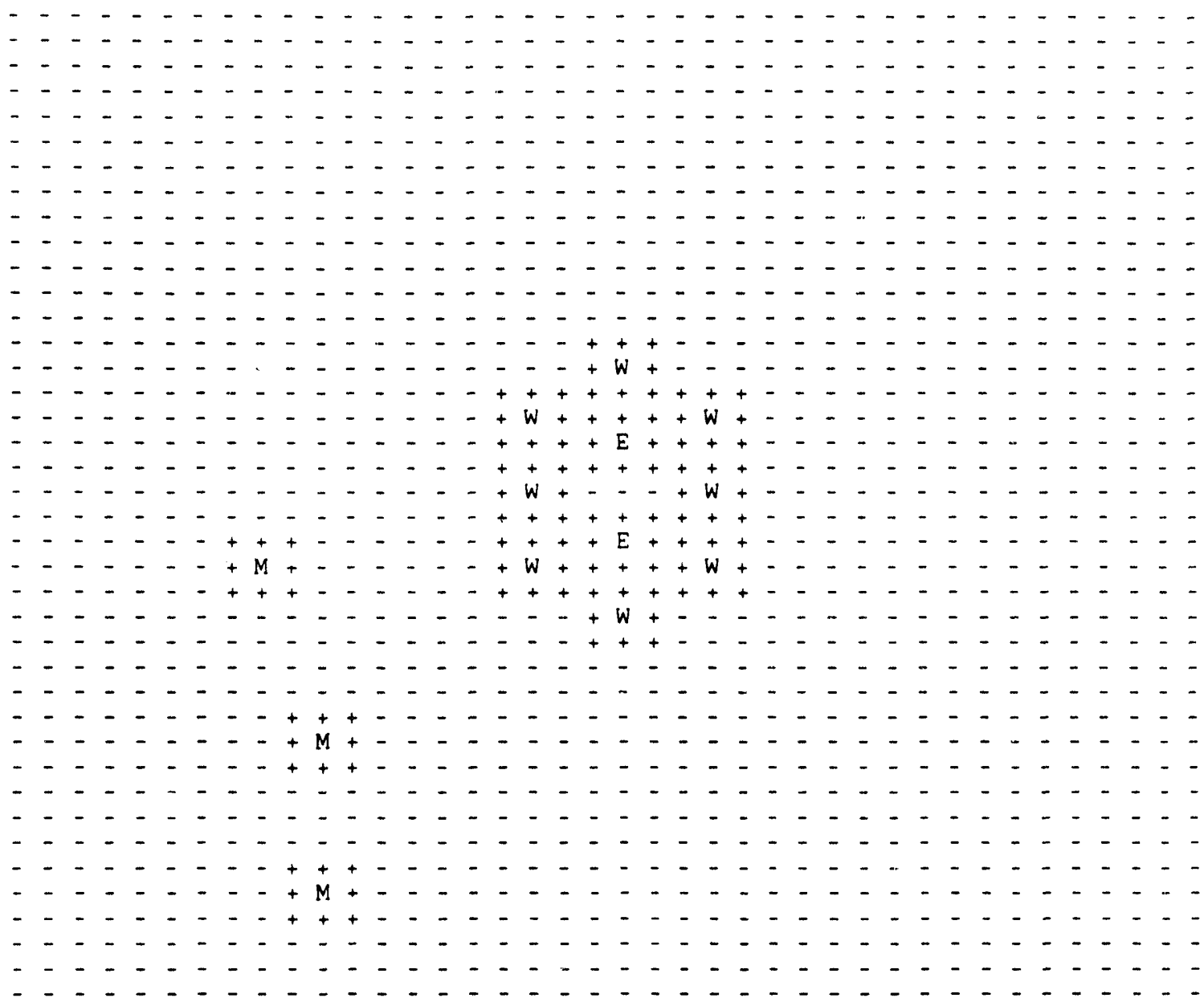

$+\quad$ denotes node is covered

- denotes node is not covered

E denotes location of extraction well

W denotes location of new .nonitoring well

M denotes location of existing monitoring well

Fig. 4. Location $A$ with all weight on drawdown and eight wells added. 
Radius of coverage $(S)=75.0$

Total number of wells $(P)=10$

Percentage covered $=7.75$

Weight for drawdown $\left(\lambda_{\text {draw }}\right)=1.00$

Weight for concentration $\left(\lambda_{\text {conc }}\right)=0.00$

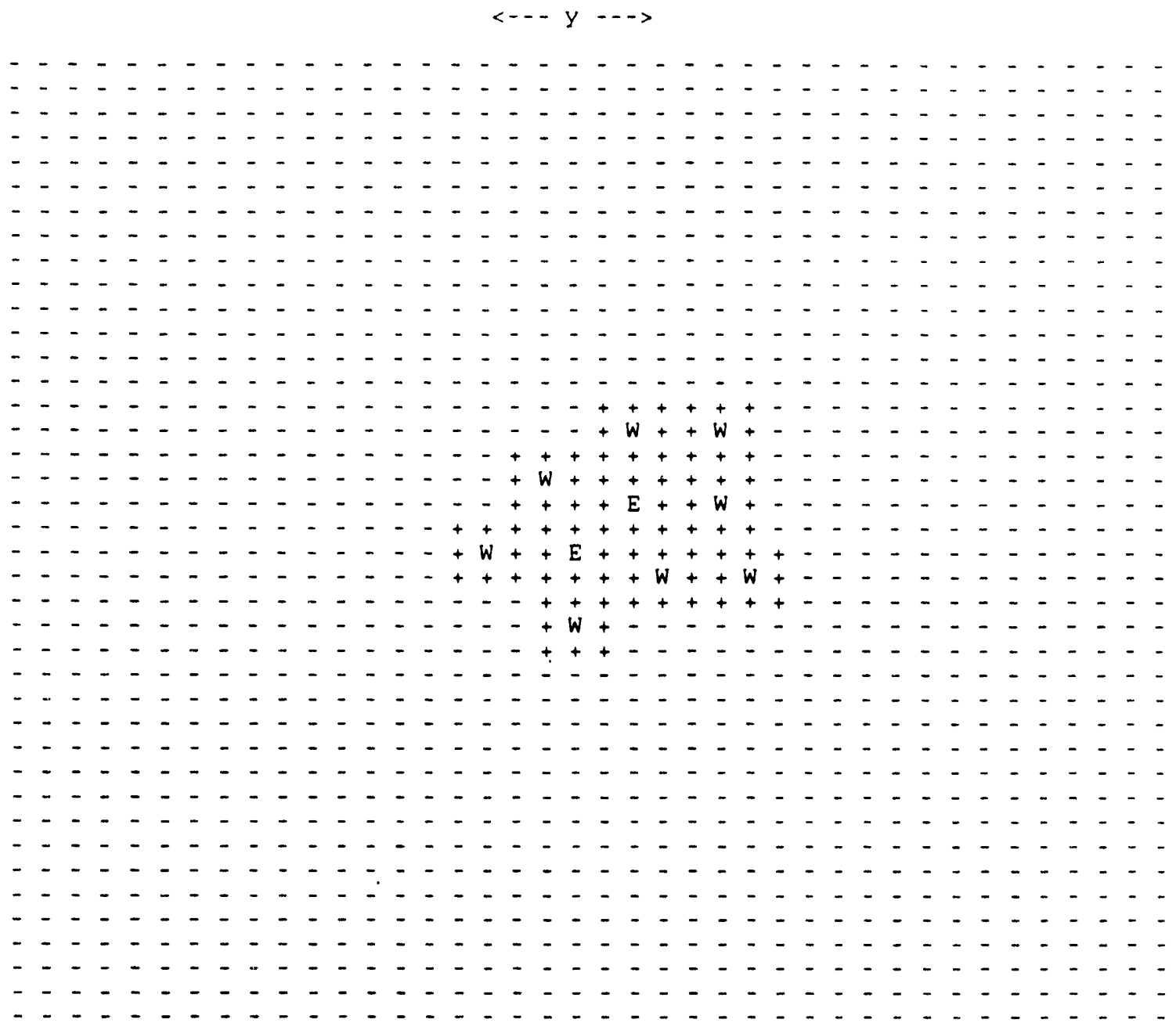

$+\quad$ denotes node is covered

- denotes node is not covered

E denotes location of extraction weil

W denotes location of new monitoring well

$M$ denotes location of existing monitoring well

Fig. 5. Location B with all weight on drawdown and eight wells added. 
Radius of coverage $(S)=75.0$

Total number of wells $(P)=9$

Percentage covered $=9.55$

Weight for drawdown $\left(\lambda_{\text {draw }}\right)=0.50$

Weight for concentration $\left(\lambda_{\text {conc }}\right)=0.50$

$\langle\cdots y-\cdots\rangle$

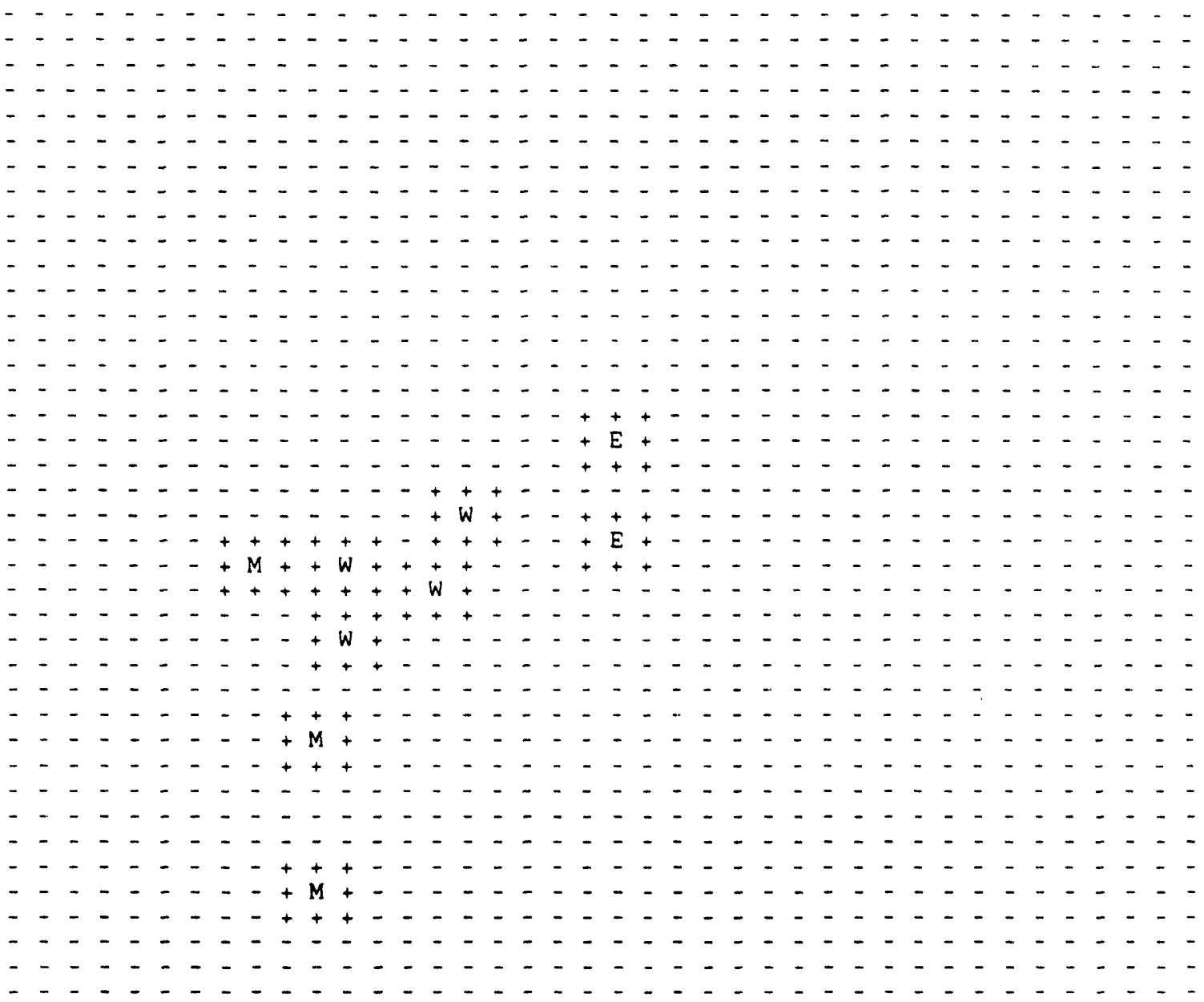

$\begin{array}{ll}+ & \text { denotes node is covered } \\ \text { E } & \text { denotes node is not covered } \\ \text { W } & \text { denotes location of extraction well } \\ \text { M } & \text { denotes location of new monitoring well }\end{array}$

Fig. 6. Location $A$ with equal weight on drawdown and concentration and six wells added. 
Radius of coverage $(S)=75.0$

Total number of wells $(P)=13$

Percentage covered $=13.47$

Weight for drawdown $\left(\lambda_{\text {draw }}\right)=0.50$

Weight for concentration $\left(\lambda_{\text {conc }}\right)=0.50$

$\langle--y-->$

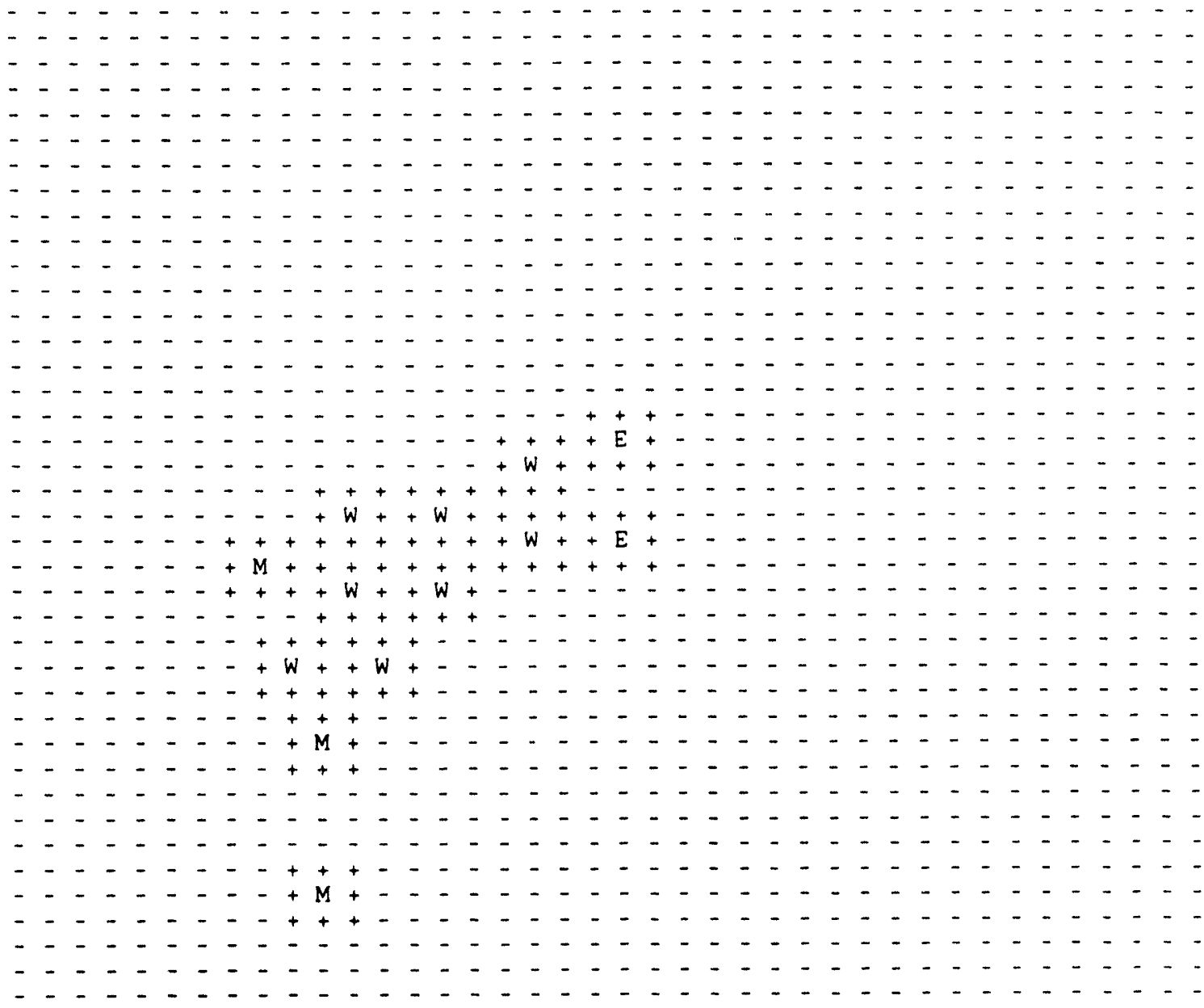

$+\quad$ denotes node is covered

- denotes node is not covered

E denotes location of extraction well

W denotes location of new monitoring well

M denotes location of existing monitoring well

Fig. 7. Location A with equal weight on drawdown and concentration and eight wells added. 
Radius of coverage $(S)=75.0$

Total number of wells $(P)=15$

Percentage covered $=15.05$

Weight for drawdown $\left(\lambda_{\text {draw }}\right)=0.50$

Weight for concentration $\left(\lambda_{\text {conc }}\right)=0.50$

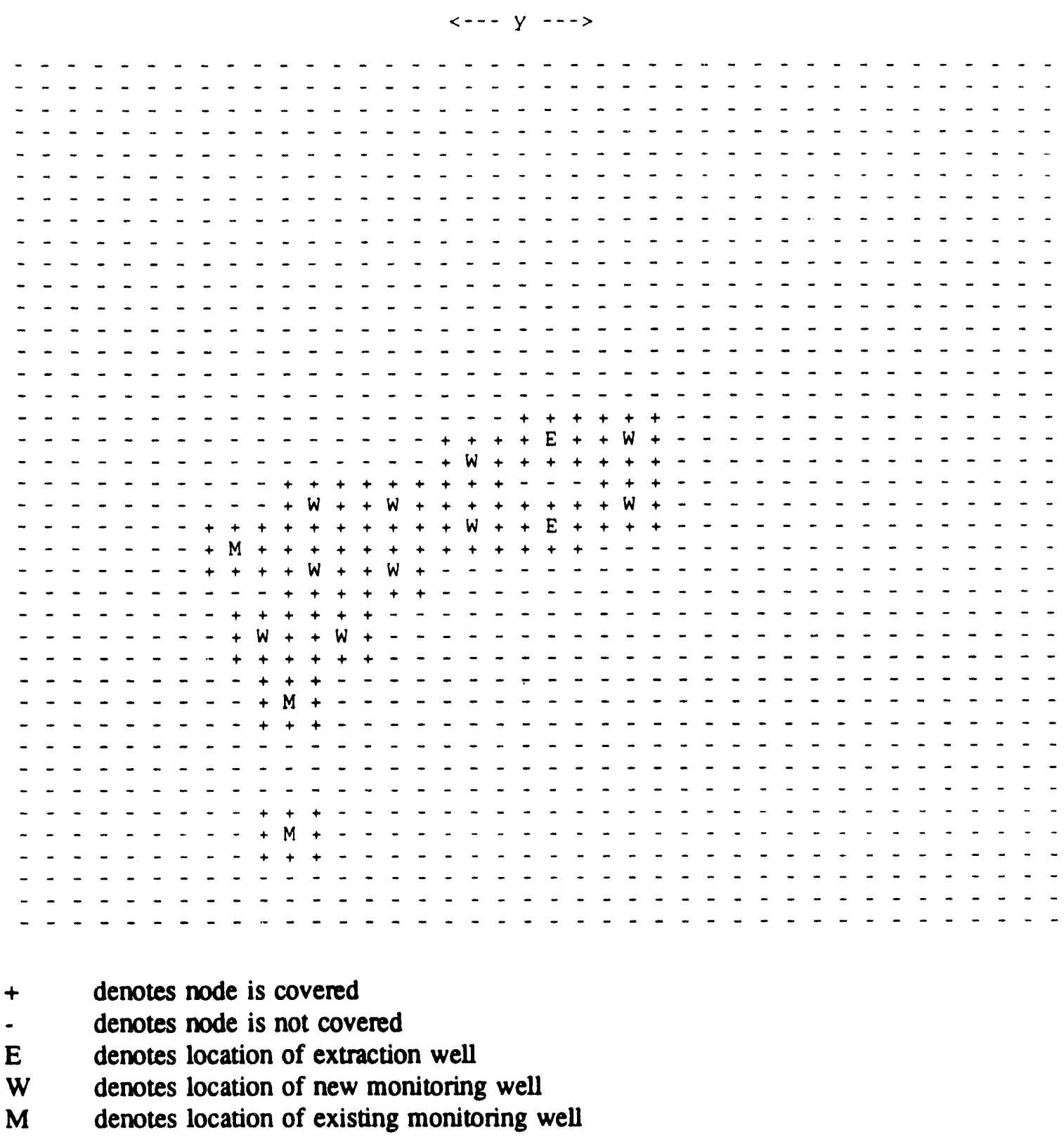

Fig. 8. Location A with equal weight on drawdown and concentration with ten wells added. 
Radius of coverage $(\mathrm{S})=75.0$

Total number of wells $(P)=10$

Percentage covered $=11.69$

Weight for drawdown $\left(\lambda_{\mathrm{draw}}\right)=0.50$

Weight for concentration $\left(\lambda_{\text {conc }}\right)=0.50$

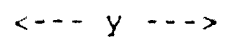



$\begin{array}{ll}+ & \text { denotes node is covered } \\ \text { - } & \text { denotes node is not covered } \\ \text { E } & \text { denotes location of extraction well } \\ \text { W } & \text { denotes location of new monitoring well } \\ \text { M } & \text { denotes location of existing monitoring well }\end{array}$

Fig. 9. Location B with equal weights on concentration and drawdown with eight wells added. 
Radius of coverage $(S)=75.0$

Total number of wells $(P)=8$

Percentage covered $=9.45$

Weight for drawdown $\left(\lambda_{\text {draw }}\right)=0.50$

Weight for concentration $\left(\lambda_{\text {conc }}\right)=0.50$

$\langle\cdots y-\cdots>$

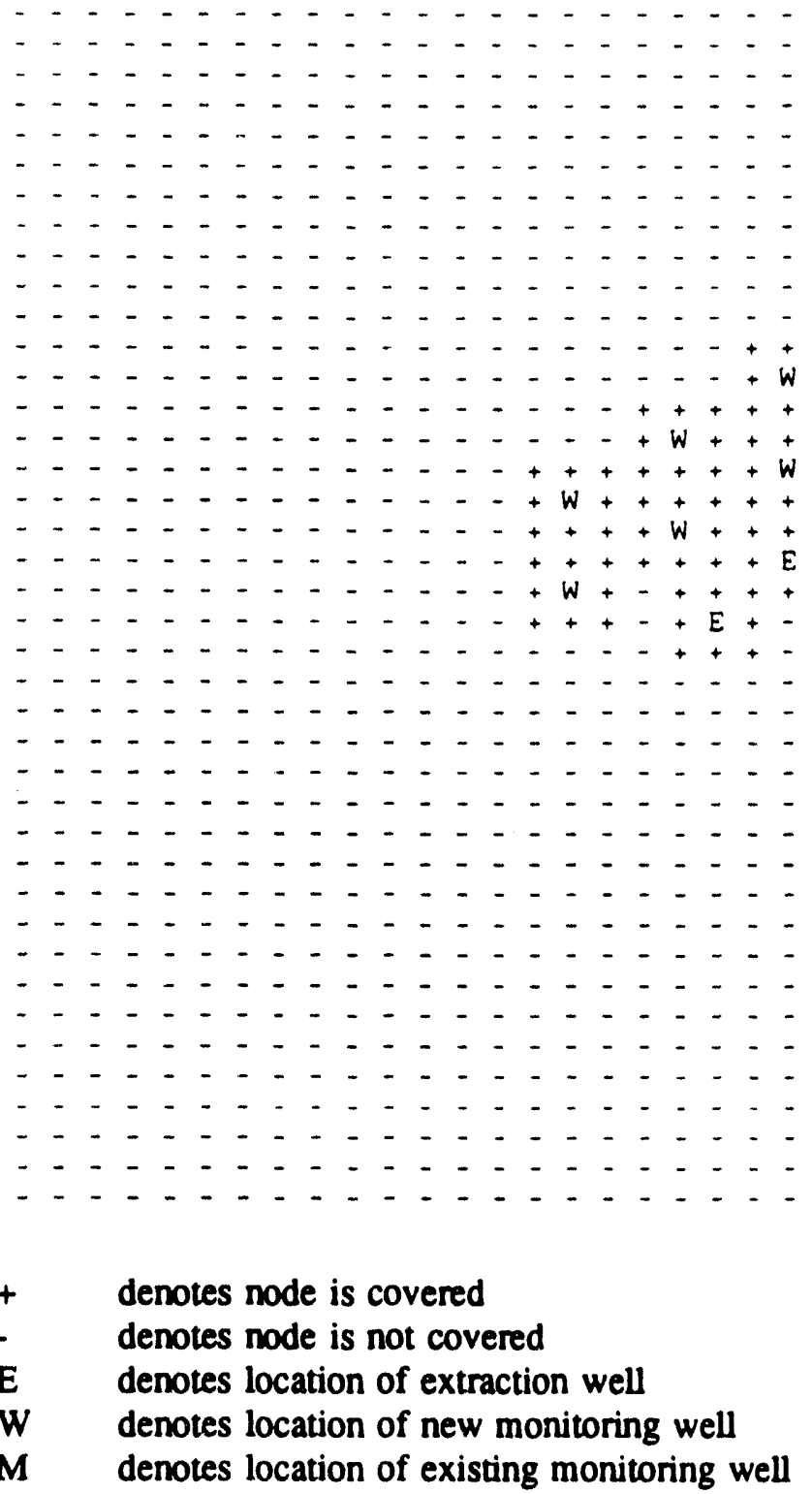

Fig. 10. Location B with equal weight on concentration and drawdown and six wells added. 
Radius of coverage $(S)=75.0$

Total number of wells $(P)=12$

Percentage covered $=13.89$

Weight for drawdown $\left(\lambda_{\text {draw }}\right)=0.50$

Weight for concentration $\left(\lambda_{\text {conc }}\right)=0.50$

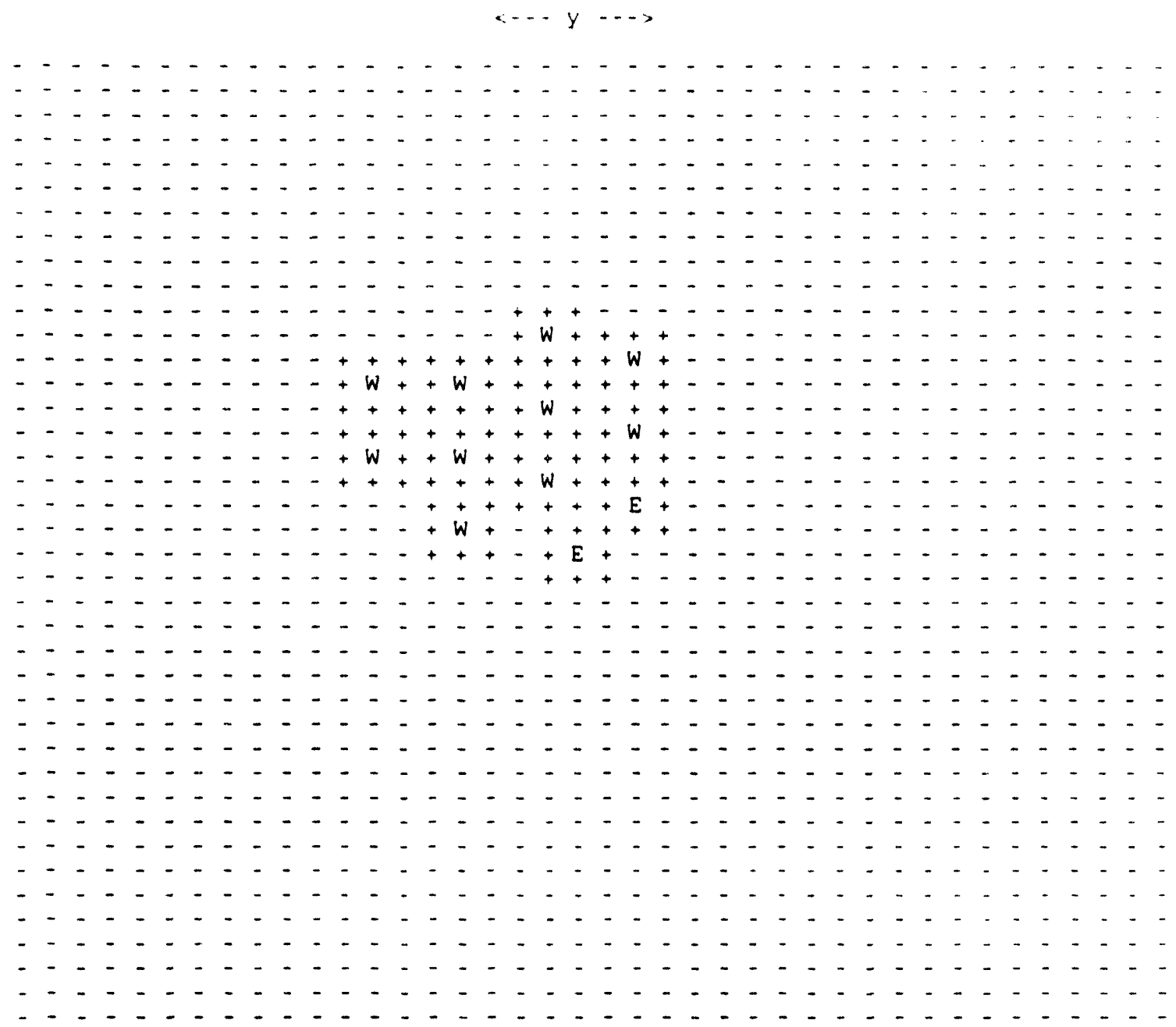

$+\quad$ denotes node is covered

- denotes node is not covered

E denotes location of extraction well

W denotes location of new monitoring well

M denotes location of existing monitoring well

Fig. 11. Location B with equal weight on concentration and drawdown, ten wells added. 
Radius of coverage $(S)=150.0$

Total number of wells $(P)=13$

Percentage covered $=37.04$

Weight for drawdown $\left(\lambda_{\text {draw }}\right)=0.50$

Weight for concentration $\left(\lambda_{\text {conc }}\right)=0.50$

$+\quad$ denotes node is covered

- denotes node is not covered

E denotes location of extraction well

W denotes location of new monitoring well

$M$ denotes location of existing monitoring well

Fig. 12. Location A with larger grid spacing, equal weights for drawdown and concentration, and seven wells added. 
Radius of coverage $(S)=150.0$

Total number of wells $(\mathrm{P})=10$

Percentage covered $=39.34$

Weight for drawdown $\left(\lambda_{\text {draw }}\right)=0.50$

Weight for concentration $\left(\lambda_{\text {conc }}\right)=0.50$

$\cdots y-\cdots$

$$
\begin{aligned}
& +W
\end{aligned}
$$

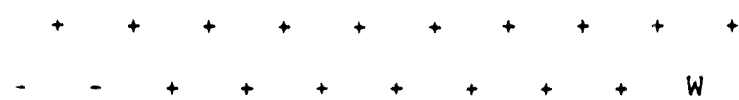

$$
\begin{aligned}
& \text { W } \\
& +\quad \text { denotes node is covered } \\
& \text { - denotes node is not covered } \\
& \text { E denotes location of extraction well } \\
& \text { W denotes location of new monitoring well } \\
& M \text { denotes location of existing monitoring well }
\end{aligned}
$$

Fig. 13. Location B with larger grid spacing, equal weights for drawdown and concentration, and eight new wells. 


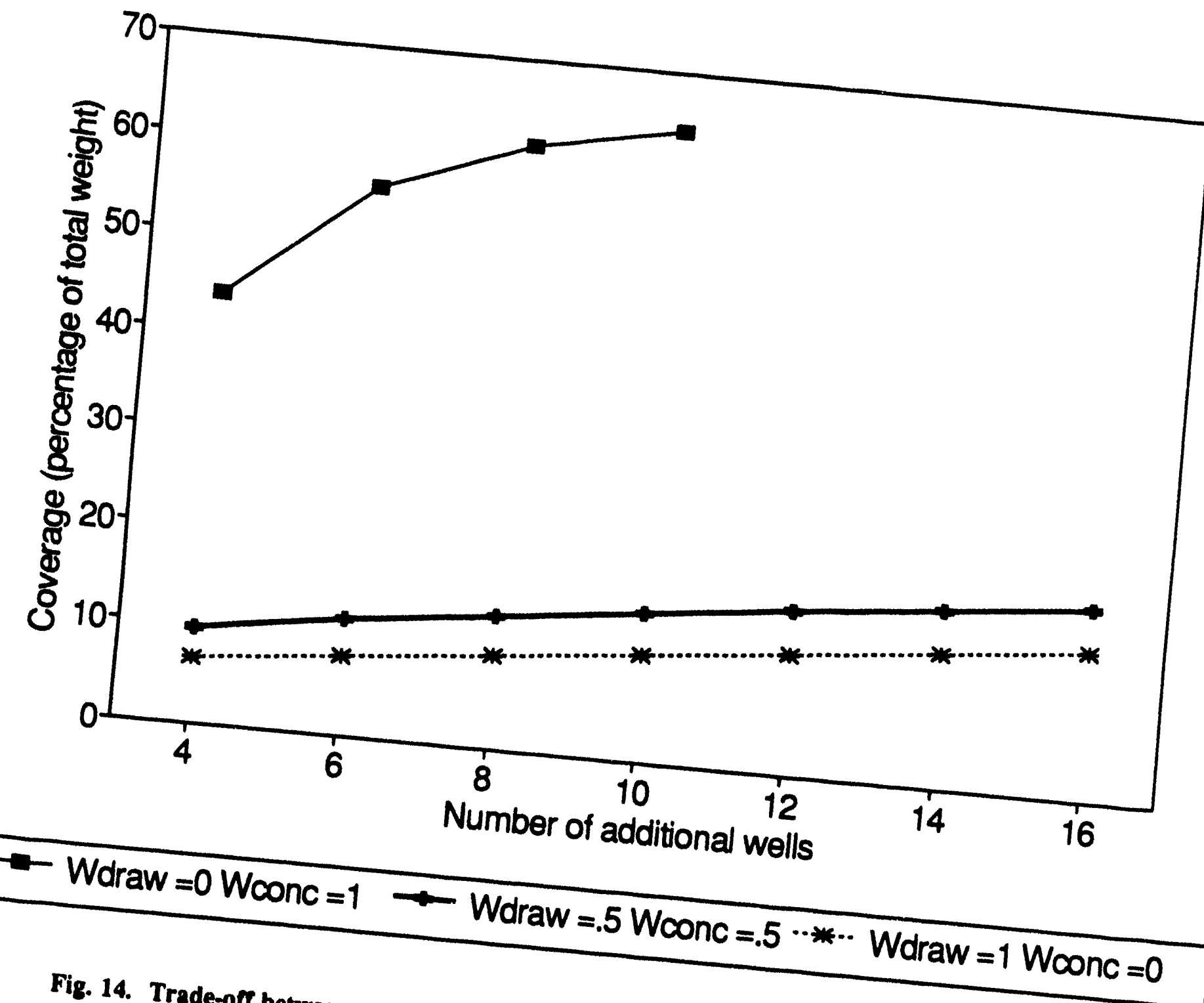

by optimal siting plan (Location $A, S=75$ ).
alls and the percent of total weight covered 


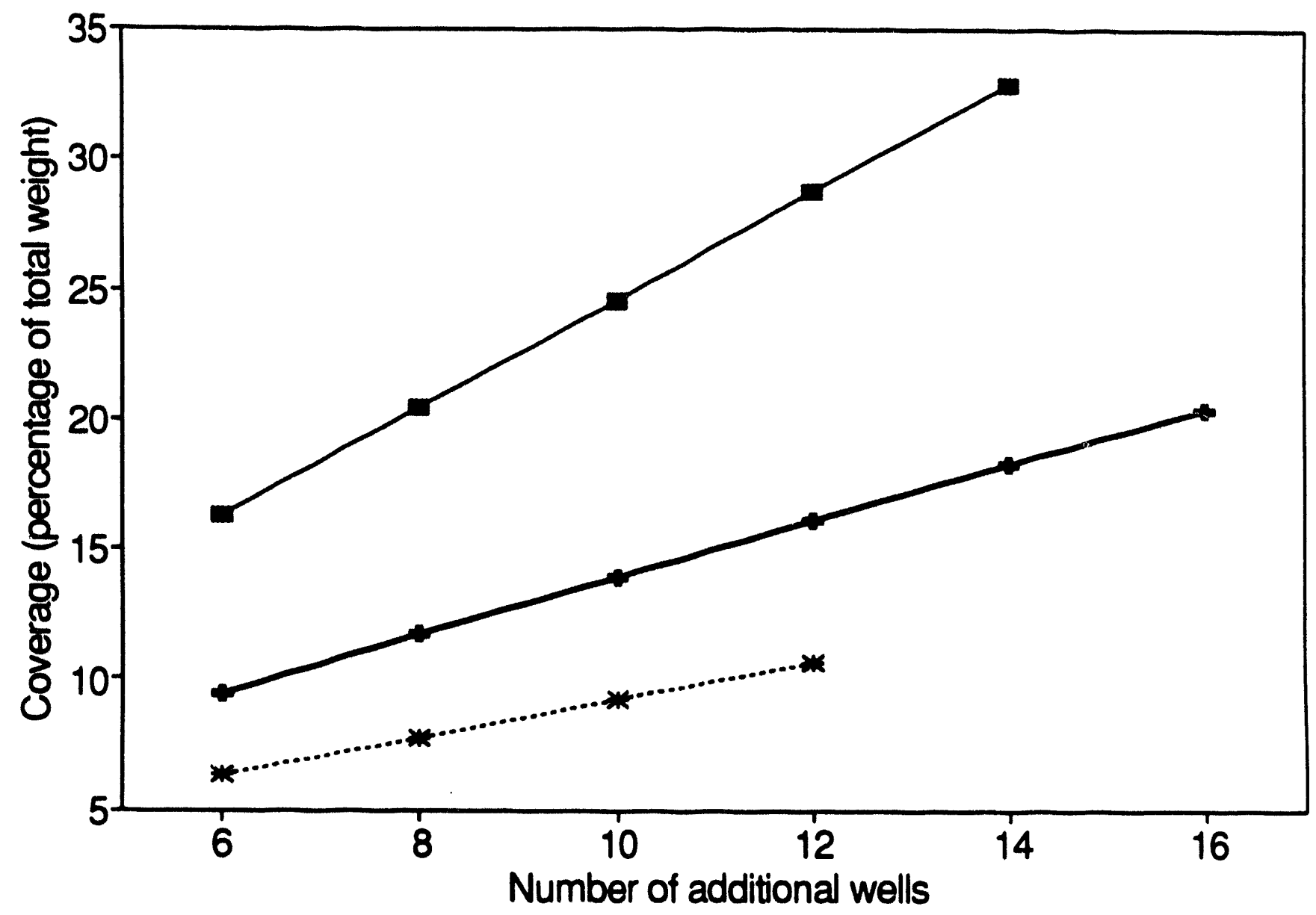

$\rightarrow$ Wdraw $=0$ Wconc $=1-$ Wdraw $=.5$ Wconc $=.5 \cdots * \cdots$ Wdraw $=1$ Woonc $=0$

Fig. 15. Trade-off between number of additional wells and the percent of total weight covered by optimal siting plan (Location B, $S=75$ ). 
Actual Well Siting Locations -- Location A -- Source Site

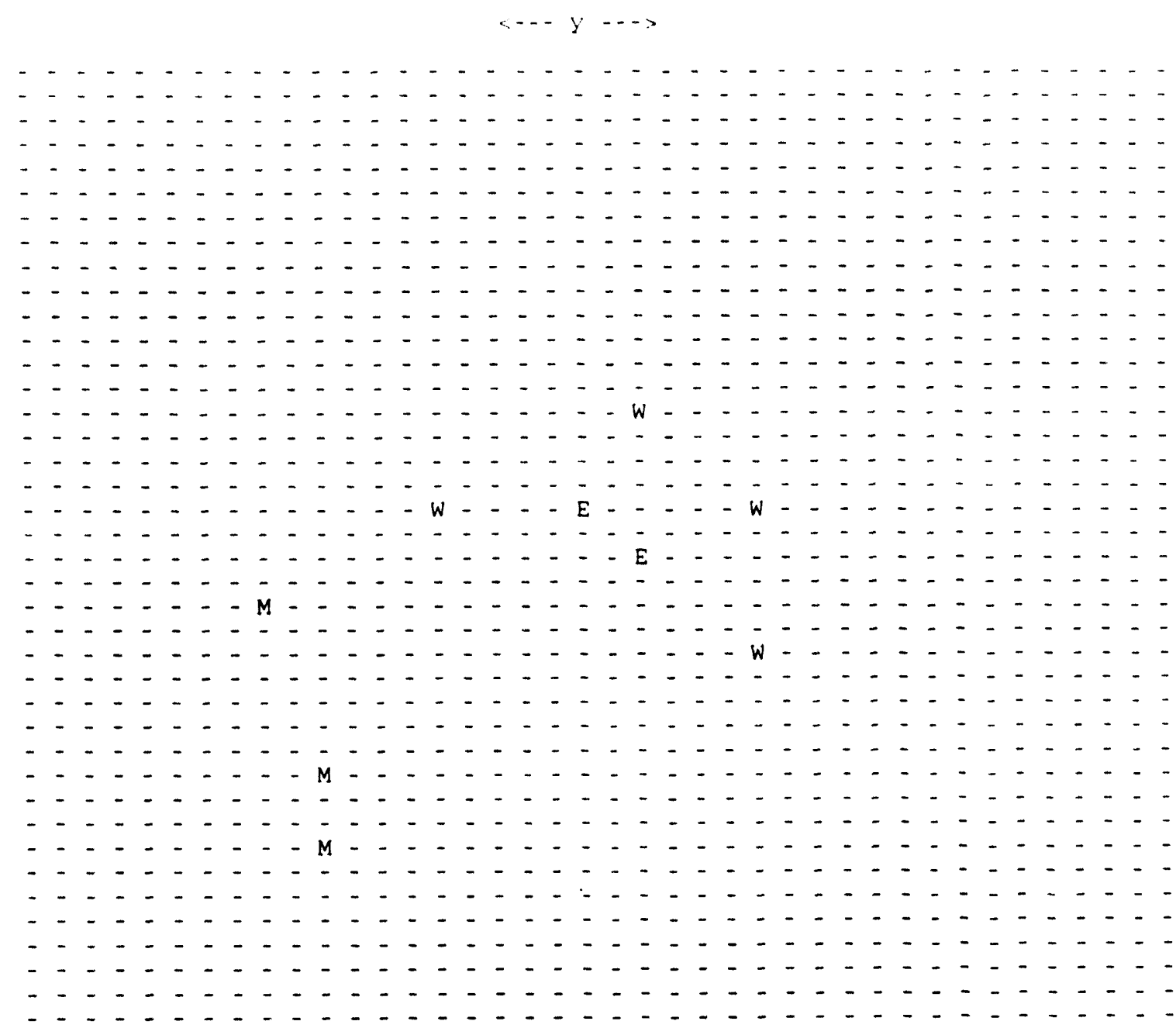

$+\quad$ denotes node is covered

- denotes node is not covered

E denotes location of extraction well

W denotes location of new monitoring well

M denotes location of existing monitoring well

Fig. 16. Actual well sites at Location A -- source site. 
Actual Well Siting Locations -. Location B -. Toe-of-the-Plume Site

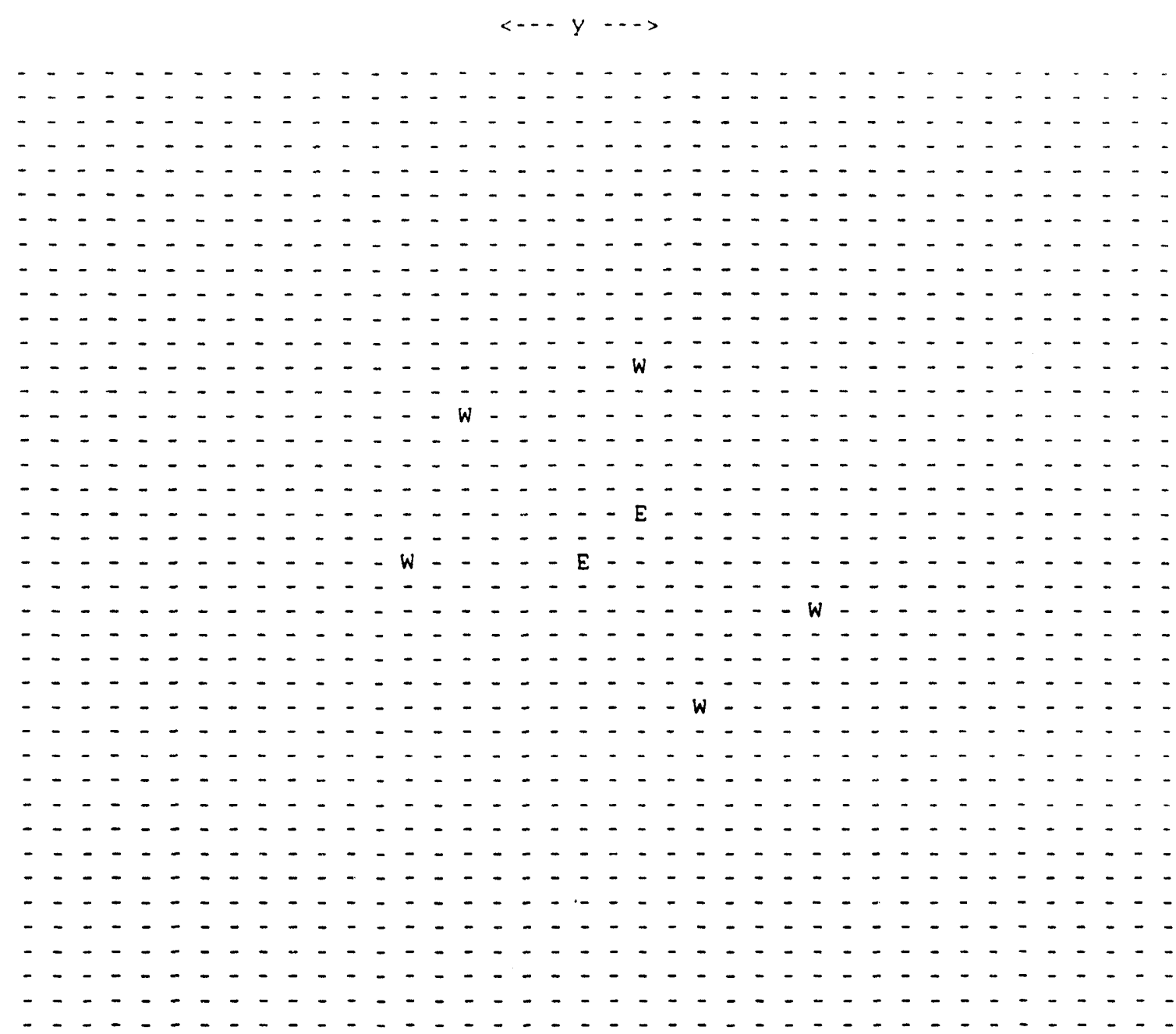

$+\quad$ denotes node is covered

- denotes node is not covered

E denotes location of extraction well

W denotes location of new monitoring well

M denotes location of existing monitoring well

Fig. 17. Actual well sites at Location B -- toe-of-the-plume site. 


\section{GenERAL DESIEN AND COMPUTATION SHEET}

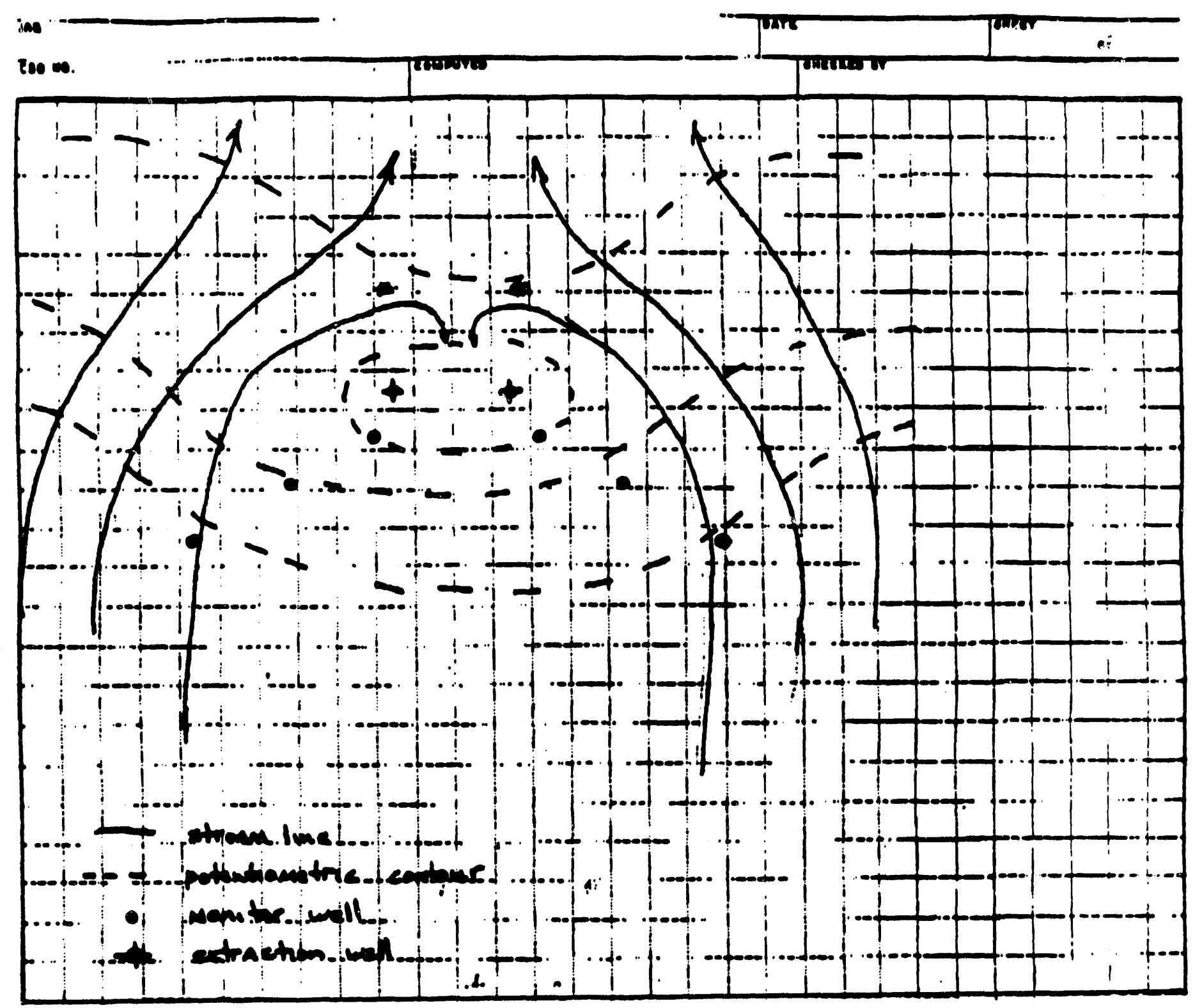

Fig. 18. Preliminary networ/s design, eight monitoring wells. 
Radius of coverage $(S)=75.0$

Total number of wells $(P)=7$

Percentage covered $=9.44$

Weight for drawdown $\left(\lambda_{\text {draw }}\right)=0.2500$

Weight for stagnation zone $\left(\lambda_{\nabla}\right)=0.2500$

Weight for concentration $\left(\lambda_{\text {conc }}\right)=0.2500$

$$
\langle--y-->
$$

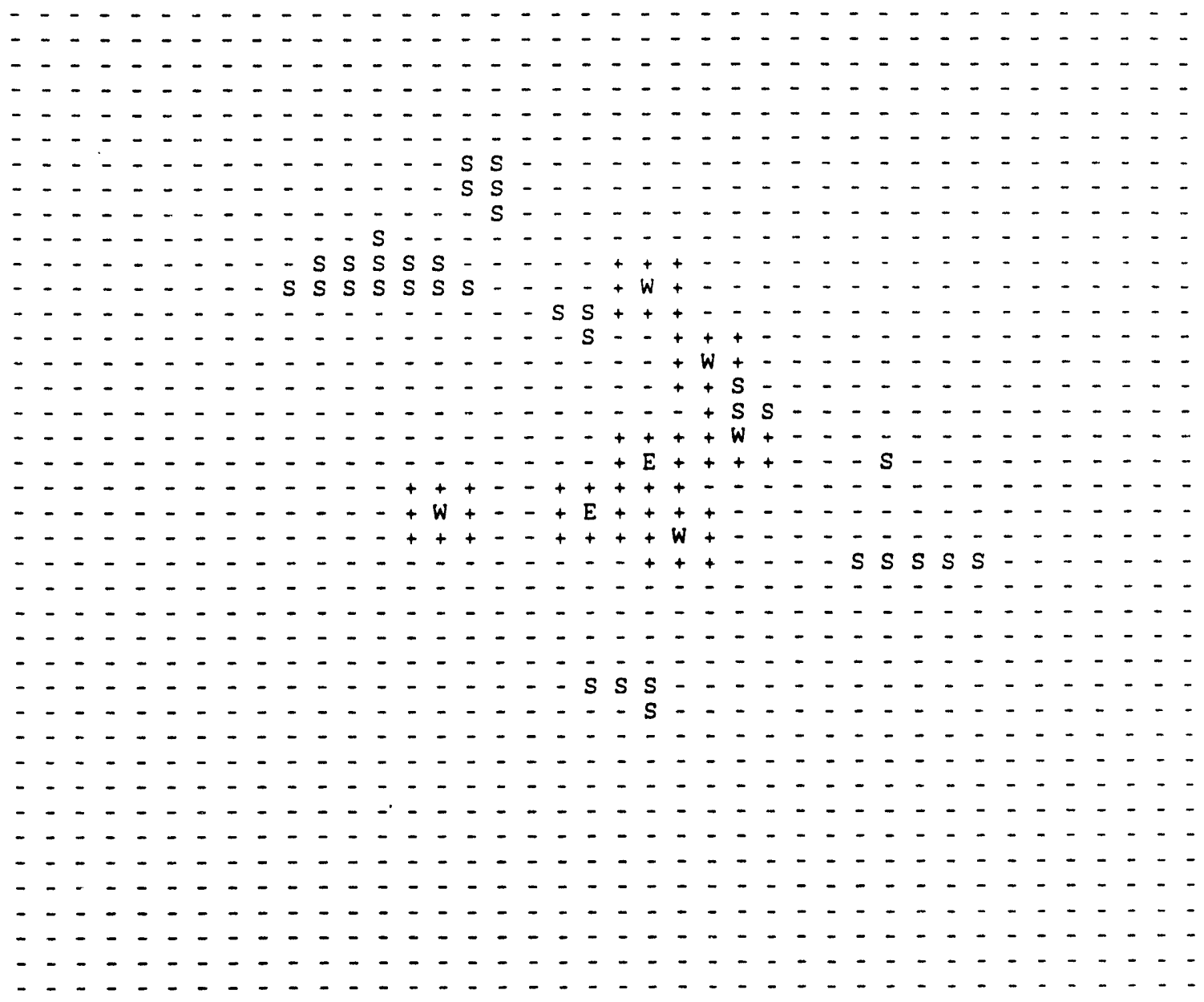

$+\quad$ denotes node is covered

- denotes node is not covered

E denotes location of extraction well

W denotes location of new monitoring well

M denotes location of existing monitoring well

Fig. 19. Location B with regular grid spacing, revised formulation, and equal weights on drawdown, concentration, and gradient objectives. 
Radius of coverage $(S)=150.0$

Total number of wells $(P)=7$

Percentage covered $=27.71$

Weight for drawdown $\left(\lambda_{\text {draw }}\right)=0.3300$

Weight for stagnation zone $\left(\lambda_{\nabla}\right)=0.3300$

Weight for concentration $\left(\lambda_{\text {conc }}\right)=0.3300$

$\langle-\cdots y-\cdots>$

$+\quad$ denotes node is covered

- denotes node is not covered

E denotes location of extraction well

W denotes location of new monitoring well

$M$ denotes location of existing monitoring well

Fig. 20. Location B with larger grid spacing, revised formulation, and equal weights on drawdown, concentration, and gradient objectives. 
Radius of coverage $(S)=150.0$

Total number of wells $(P)=7$

Percentage covered $=18.55$

Weight for drawdown $\left(\lambda_{\text {draw }}\right)=1.0000$

Weight for stagnation zone $\left(\lambda_{\nabla}\right)=0.0010$

Weight for concentration $\left(\lambda_{\text {conc }}\right)=0.0010$

$+\quad$ denotes node is covered

- denotes node is not covered

E denotes location of extraction well

W denotes location of new monitoring well

M denotes location of existing monitoring well

Fig. 21. Location B with larger grid spacing, revised formulation, and all weight on drawdown. 

L. V. Asplund
G. R. Miller
P. E. Bamdt
G. R. Moline
R. O. Barnett
G. K. Moore
L. D. Bates
C. A. Motley
R. P. Baxter
J. B. Murphy
D. T. Bell
M. J. Norris
G. W. Bodenstien
R. S. Poling
H. L. Boston
D. E. Reichle
H. E. Cardwell (5)
C. T. Rightmire
K. W. Cook
T. H. Row
T. K. Cothrom
M. J. Sale (5)
J. H. Cushman
F. E. Sharples
F. P. Delozier
D. S. Shriner
J. W. Douthitt (5)
E. D. Smith
R. B. Dreier
S. H. Stow
T. O. Early
L. E. Toran
J. M. Forstrom
L. O. Vaughan
D. E. Fowler
S. H. Welch
C. W. Gehrs
R. K. White
P. A. Gourieux
S. L. Winters
J. T. Grumskj
T. F. Zondlo
S. G. Hildebrand
ESD Library (15)
D. D. Huff (5)
Laboratory Records Dept. (2)
W. K. Jago
Laboratory Records, ORNL-RC
K. G. Kahl
ORNL Patent Section
P. Kanciruk
ORNL Y-12 Technical Library
A. J. Kuhaida 


\section{EXTERNAL DISTRIBUTION}

R. N. Farvolden, Professor, Department of Earth Sciences, University of Waterloo, Waterloo, Ontario N2L 3G1 Canada

R. C. Harriss, Institute for the Study of Earth, Oceans, and Space, Science and Engineering Research Building, University of New Hampshire, Durham, NH 03824

G. Y. Jordy, Director, Office of Program Analysis, Office of Energy Research, ER-30, G-226, U.S. Department of Energy, Washington, DC 20545

A. Patrinos, Director, Environmental Sciences Division, Office of Health and Environmental Research, ER-74, U.S. Department of Energy, Washington, DC 20585

F. J. Wobber, Environmental Sciences Division, Office of Health and Environmental Research, ER-74, U.S. Department of Energy, Washington, DC 20585

Office of Assistant Manager for Energy Research and Development, U.S. Department of Energy Oak Ridge Operations, P.O. Box 2001, Oak Ridge, TN 37831-8600

(2) Office of Scientific and Technical Information, P.O. Box 62, Oak Ridge, TN 37831 
$r$
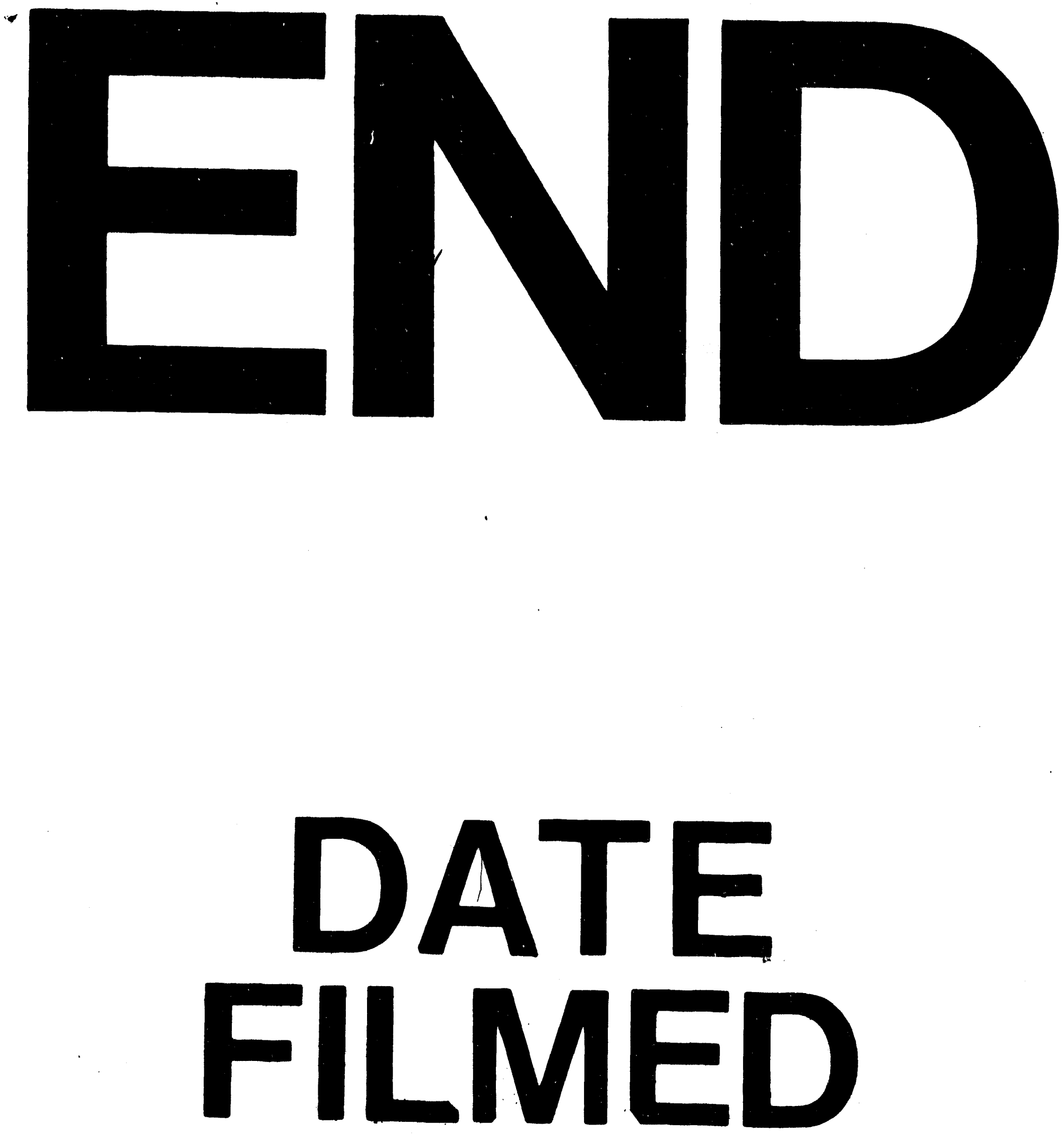

1

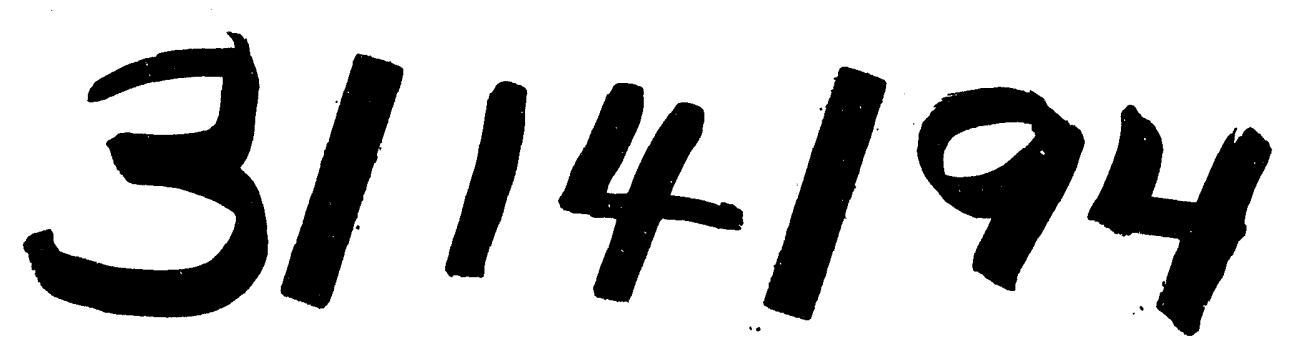




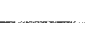

- 